\title{
Effects of chronic consumption of specific fruit (berries, citrus and cherries) on CVD risk factors: a systematic review and meta-analysis of randomised controlled trials
}

\author{
Yueyue Wang $^{1} \cdot$ Jose Lara Gallegos ${ }^{1} \cdot$ Crystal Haskell-Ramsay $^{2} \cdot$ John K. Lodge $^{1}$ (i)
}

Received: 23 March 2020 / Accepted: 5 June 2020 / Published online: 13 June 2020

(c) The Author(s) 2020

\begin{abstract}
Purpose This review aims to compare the magnitude of the effects of chronic consumption of fruits; specifically berries, citrus and cherries on cardiovascular disease (CVD) risk factors.

Methods PubMed, Web of Science, Scopus, and psycARTICLES were searched from inception until January 2020. Fortyfive chronic ( $\geq 1$ week) randomised controlled trials assessing CVD risk factors including endothelial (dys)function, blood pressure (BP), blood lipids and inflammatory biomarkers were included.

Results Investigated interventions reported improvements in endothelial function $(n=8)$, inflammatory biomarkers and lipid status $(n=14)$, and BP $(n=10)$. Berries including juice of barberry, cranberry, grape, pomegranate, powder of blueberry, grape, raspberry and freeze-dried strawberry significantly reduced SBP by $3.68 \mathrm{mmHg}(95 \% \mathrm{CI}-6.79$ to $-0.58 ; P=0.02)$ and DBP by $1.52 \mathrm{mmHg}(95 \% \mathrm{CI}-2.87$ to $-0.18, P=0.04)$. In subgroup analysis, these associations were limited to cranberry juice (SBP by $1.52 \mathrm{mmHg}$ [ $95 \% \mathrm{CI}-2.97$ to $-0.07 ; P=0.05$ ], DBP by $1.78 \mathrm{mmHg}$ [95\% CI -3.43 to -0.12 , $P=0.04]$ and cherry juice (SBP by $3.11 \mathrm{mmHg}[95 \% \mathrm{CI}-4.06$ to $-2.15 ; P=0.02]$ ). Berries also significantly elevated sVCAM-1 levels by $14.57 \mathrm{ng} / \mathrm{mL}$ ( $85 \%$ CI 4.22 to $24.93 ; P=0.02$ ).

Conclusion These findings suggest that supplementing cranberry or cherry juice might contribute to an improvement in blood pressure. No other significant improvements were observed for other specified fruits. More research is warranted comparing different classes of fruit and exploring the importance of fruit processing on their cardiovascular-protective effects.
\end{abstract}

Keywords Fruit $\cdot$ Intervention $\cdot$ Endothelial function $\cdot$ CVD risk factors $\cdot$ Systematic review $\cdot$ Meta-analysis

\section{Introduction}

Current World Health Organization (WHO) recommendations for fruit intake combined with vegetable intake are a minimum $400 \mathrm{~g} /$ day [1]. A recent meta-analysis indicated

Electronic supplementary material The online version of this article (https://doi.org/10.1007/s00394-020-02299-w) contains supplementary material, which is available to authorized users.

John K. Lodge

john.lodge@northumbria.ac.uk

1 Department of Applied Sciences, Faculty of Health and Life Sciences, Northumbria University, EBD223 Ellison Building, Newcastle upon Tyne NE1 8ST, UK

2 Department of Psychology, Faculty of Health and Life Sciences, Northumbria University, Newcastle-upon-Tyne, UK that the intake of $800 \mathrm{~g} / \mathrm{day}$ of fruit was associated with a $27 \%$ reductions in relative risk of CVD [2]. It is well recognised that cardiovascular health can be affected by several dietary factors [3]. Epidemiological evidence has established strong inverse associations between flavonoid-rich fruit (e.g. strawberries, grapefruit) and coronary heart disease (CHD) mortality in CVD-free postmenopausal women after multivariate adjustment [4]. Endothelial function is a primary indicator of cardiovascular health, a damaged endothelium will cause disruption of vascular hemostasis and further lead to endothelial dysfunction, which is the manifestation underlying atherosclerosis, hypertension, and other CVDs $[5,6]$. Intervention studies also provide evidence supporting the consumption of a range of fruit and fruit juice to reduce cardiovascular dysfunction risk factors. For example, consumption of fruit containing relatively high levels of anthocyanins and procyanidins, such as berries, has been shown to improve CVD risk factors, namely endothelial dysfunction, 
dyslipidaemia, platelet aggregation, and hypertension [7, 8], whereas flavanone-rich citrus, such as orange, were effective in improving hypercholesterolaemia [7]. The consumption of cherries was also suggested by interventions to promote cardiovascular health by preventing or decreasing lipid levels and inflammation [9]. One systematic review and epidemiological evidence have also revealed that the consumption of fruit juice including citrus, berries and cherry juice may benefit vascular health by affecting risk markers such as blood pressure and lipid profiles $[10,11]$.

Fruit juice and powder may be effective methods to increase overall fruit consumption, which may explain the emerging intervention studies investigating health benefits with fruit powder and juice supplementations. With regard to nutritional value, freeze-dried fruit powder that is devoid of water retains concentrated bio-accessible antioxidants, fibre and other components [10]. Research has suggested that the juicing process can lead to a lower content of fibre and certain bioactives such as polyphenols, vitamins, and minerals $[12,13]$, while other research suggests that processing can increase the bioavailability of carotenoids, such as lycopene [14]. A recent single-dose bioavailability study showed only minor differences between whole blueberry fruit and blueberry juice [15]; indeed a systematic review demonstrated that the intake of fruit and vegetable juice offered similar cardiovascular health benefits to the intake of whole fruit and vegetables [16].

Other systematic reviews have assessed the effect of fruit and vegetable intake on endothelial function or the effect of specific fruit juice intake on CVD risk factors [17, 18]. However, to the best of our knowledge, the effects of the fruitdelivery method (type and processed form) in relation to CVD risk factors including endothelial (dys)function, lipid profile (i.e. total cholesterol) and inflammatory biomarkers (i.e. C-reactive protein/CRP) has not been appraised. A review of this type is important to clarify the evidence base for the type and form of fruit that is most cardiovascularprotective. Therefore, the aim of this study was to systematically review and meta-analyse available human intervention studies to evaluate the potential effect of consumption of whole, freeze-dried, powdered, and juiced forms of fruit, and specifically berry, citrus and cherry fruit, on CVD risk factors in randomised controlled trials (RCTs) in line with the PICOS (population, intervention, comparator, outcome, study design) framework (Supplemental Table 1).

\section{Methods}

\section{Study eligibility}

We searched for studies assessing the effect of specific fruit supplementations on CVD risk factors including terms of "fruit", "CVD risk factors", "endothelial function", "BP", "lipid", "inflammatory biomarker". The following specific inclusion criteria were applied: (1) study design: RCTs; (2) subjects: adult subjects $\geq 18$ years of age; (3) interventions: intervention RCTs providing or promoting berry, or cherry or citrus fruit or their juice or freeze-dried, or powdered fruit consumption; (4) intervention length: at least 1 week; (5) control: control groups without components of citrus fruit, cherry, or berries, likely placebo group; (6) outcomes: the primary outcomes were the whole body measurements: systolic and diastolic blood pressure (SBP and DBP) and the endothelial (dys)function assessed by flow-mediated dilation (FMD) and pulse wave velocity (PWV); the secondary outcomes were the blood biomarkers including circulating fatty acids triglycerides (TAGs) and total cholesterol (TC), low-density lipoprotein cholesterol (LDL-C) and highdensity lipoprotein (HDL-C); inflammatory biomarkers such as high-sensitivity C-reactive protein (hsCRP), nitric oxide (NO), intercellular adhesion molecules (ICAMs) and vascular adhesion molecules (VCAMs) were also explored (described below); (7) only English-language and peerreviewed articles were included. No restriction of publication year was applied.

\section{Data sources}

The present systematic review and meta-analysis was conducted in accordance with Cochrane [19] and Centre for Reviews and Dissemination guidelines [20] and was reported according to PRISMA guidelines [21] (Supplemental Table 2). The protocol has been registered with PROSPERO, the International Prospective Register of Systematic Reviews (Registration number CRD42018091896). Such protocol includes the investigation of the impact of these fruits on cognitive function, however this analysis will be reported elsewhere. Two researchers (YW, JLG) assessed articles independently for inclusion eligibility. The searches using PubMed, Web of Science, Scopus and psycARTICLES were conducted from inception until January 2020. No restriction of publication year was applied and the search result covered studies published between 1960 and 2020.

The search of the investigated themes in this review was undertaken using terms as following: (1) fruit; (2) citrus; (3) orange; (4) berry; (5) berries; (6) grape; (7) blueberry; (8) blueberries; (9) blackberry; (10) blackberries; (11) raspberry; (12) raspberries; (13) cranberry; (14) cranberries; (15) cherry; (16) cherries; (17) "endothelial function"; (18) "vascular function"; (19) "vascular risk factors"; (20) hypertension; (21) "blood pressure"; (22) BP; (23) "pulse wave velocity"; (24) PWV; (25) "flow-mediated dilation"; (26) FMD; (27) lipid; (28) cholesterol; (29) LDL; (30) HDL; (31) triglyceride; (32) biomarkers; (33) inflammatory; (34) "Nitric Oxide"; (35) NO; (36) ICAM; (37) VCAM; (38) 
hsCRP; (39) trial; (40) intervention. Search strategy was supplied (Supplemental Table 3).

\section{Study selection}

YW and JLG selected articles independently for eligibility. Articles were moved to the next screening phase or discarded when full disagreement was reached. JKL served as an arbitrator if any disagreements that were not resolved. No disagreements occurred during the selection phase. All records were exported to EndNote X8 reference management software. The selection of eligible studies was based on two steps. Firstly, the title and abstract of each study were screened for relevance; full texts were then reviewed for those without certainty for inclusion. Reference lists of included papers and relevant systematic reviews were also screened by hand-searching for additional articles.

\section{Data abstraction}

Data were extracted by YW and JLG independent of each other, their selections for accuracy were reviewed in meeting. Corresponding authors were contacted via e-mail to request information if there were missing data or for clarification. Data from endpoints and the baseline were obtained. A pre-defined data extraction form in Microsoft Excel 2016 was used to input studies data, which includes information on (1) author and published year; (2) study design; (3) population characteristics (ethnicity, mean age, sex, mean body mass index (BMI), health status and sample size at baseline); (4) treatment details (intervention type, length, dosage and frequency); (5) control group settings; (6) retention rate; (7) measured outcomes for both experimental group and placebo group at baseline and the longest post-intervention time point to avoid the bias of selectively choosing data.

\section{Risk of bias assessments}

Study quality for RCTs was assessed by Jadad Score (0-5), which takes into account whether a trial was randomised and blinded with appropriate procedure, and whether dropouts were well recorded; a score $\geq 3$ indicates a high-quality trial [22].

Publication bias was assessed by Funnel plot and Egger's test, 'trim and fill' method was implemented to identify and correct for funnel plot asymmetry arising from publication bias [23] (Supplemental Fig. 1).

\section{Data synthesis}

$\mathrm{R}$ studio version 3.5.2 [24] and the package "meta" [25] were used to pool and meta-analyse data from collected studies. Subgroup analysis with at least 10 studies supplementing berries was implemented to estimate separate effects of different types of berries and the heterogeneity for each berry intervention subgroup. There were 3 studies supplementing grapefruit juice and cherry juice as concentrate instead of $100 \%$ juice, which could cause variations to the juice quality and bioavailability [26-28]. For example, anthocyanins are better preserved in purees (57\%) than in clarified juice (31\%) when comparing different forms of processed blackberries [29]. Sensitivity analysis of juice quality was carried out to investigate the effect of juice on the meta-analysis results.

All pooled results were presented as weighted mean difference with 2 -sided $p$ values. 95\% confidence intervals (CIs) and prediction intervals were both presented in the results. The FMD value was expressed in percentage unit and the PWV value was expressed in $\mathrm{m} / \mathrm{s}$; the conversion of $\mathrm{cm} / \mathrm{s}$ to $\mathrm{m} / \mathrm{s}$ for PWV value was applied when necessary for pooled mean differences in meta-analysis. For blood lipids, the conversion factor $1 \mathrm{mmol} / \mathrm{L}=38.67 \mathrm{mg} /$ $\mathrm{dL}$ was used for total, HDL, and LDL cholesterol level and $1 \mathrm{mmol} / \mathrm{L}=88.57 \mathrm{mg} / \mathrm{dL}$ for triglycerides level [30] where applicable.

The Hartung-Knapp-Sidik-Jonkman method for random-effects meta-analysis [31] was applied. Heterogeneity was estimated by Cochrane $Q$ statistics and the consistency of study results was assessed by $I^{2}$ statistics as an extension of Cochrane $Q$ statistics and an $I^{2}>50 \%$ is considered for a high heterogeneity level [32]. The effect sizes based on the weighted mean difference (WMD) between treatment groups were used when measurement units of assessed outcomes were comparable across studies. The standardised mean difference (SMD) was used when studies have used different measurement units and the conversion had failed.

\section{Results}

\section{Literature search}

In accordance with PRISMA guidelines [21], Fig. 1 describes the selection process of included studies. The initial search produced 13,861 articles from the four databases, this record was reduced to 8613 articles after duplicates were removed. After screening of the titles and abstracts for eligibility, 51 articles were included and 10 additional articles were added from manual search through reference lists of initially identified articles. The final selection identified 61 trials assessing CVD risk factors, where 16 articles were further excluded after checking full-text eligibility (Supplemental Table 4). Finally 45 trials were included in this review, 38 trials from these were included in the meta-analysis. 


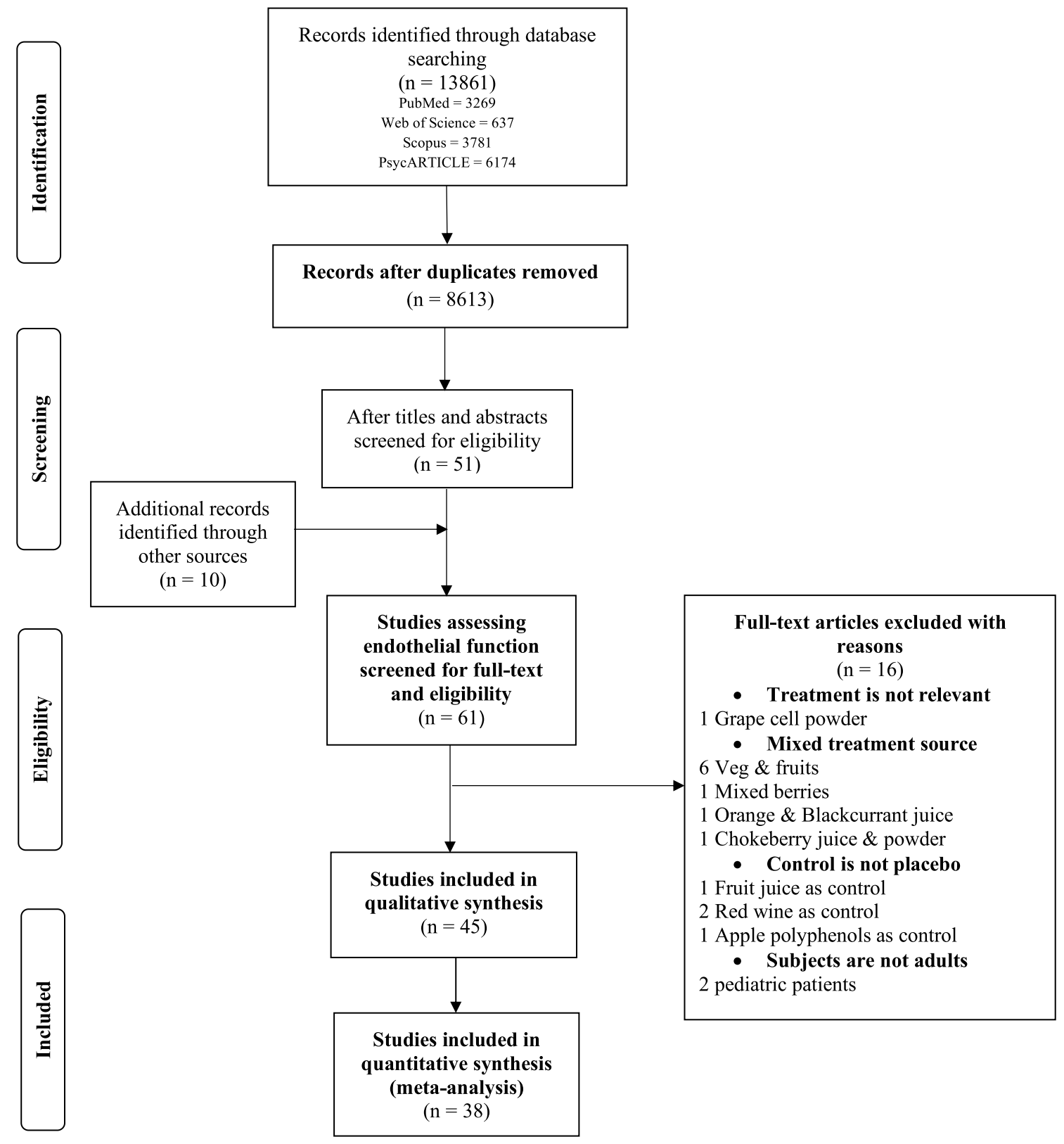

Fig. 1 Flow diagram of study selection for the review according to PRISMA guidelines

\section{Study characteristics}

Forty-five studies were included in this systematic review, of which 18 were crossover randomised controlled trials (RCT) [27, 33-49], and 27 were parallel RCTs [26, 28, 50-74] (see Table 3). The sample size of both experimental and control group in the interventions ranged from 5 to 63 . The total sample size for the intervention group was 1130; the total sample size for the control group was 1109. Participants' characteristics at baseline also vary across studies; most trials recruited healthy subjects $(n=13)$, while there were 7 studies with participants manifesting increased CVD risks (deteriorated lipid profiles and hypertension) and 3 with diagnosed CVD/CHD; 18 with metabolic syndrome (inclusive of overweight); 1 with mild-to-moderate dementia, 1 with chronic obstructive pulmonary disease, 1 with type 2 diabetes and 1 with end-stage renal disease (Table 3 ).

Results from 32 studies ( $71 \%$ of the interventions) that supplemented fruit juice are shown in Table 1, while studies supplementing whole fruit and fruit in other freeze-dried forms (13 studies), are presented in Table 2. Study effects are represented with greyscales in corresponding with reported positive, negative effects and no effect compared to either control or baseline data. Treatments were all delivered in 
Table 1 Qualitative summarisation for fruit juice interventions

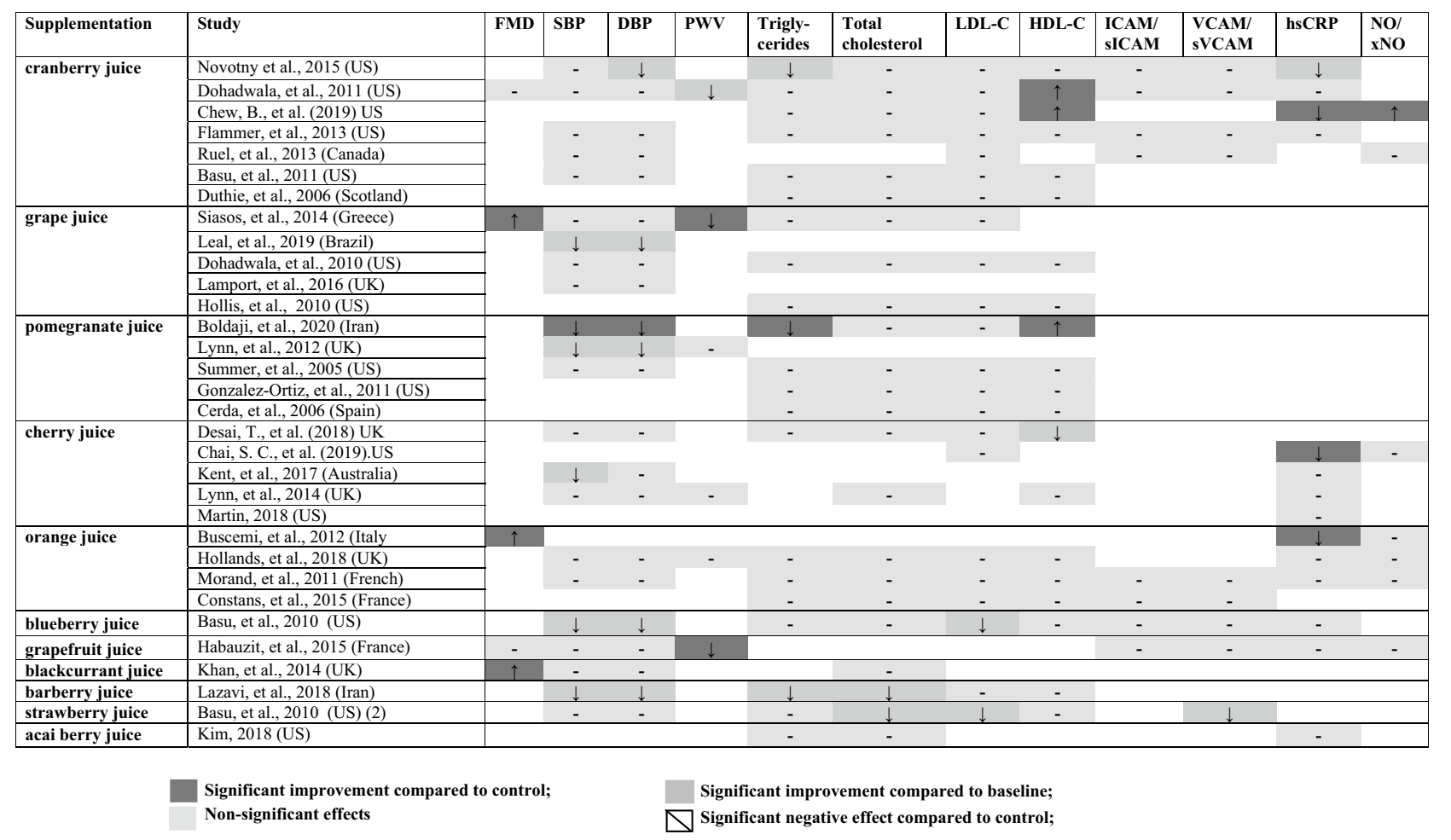

Table 2 Qualitative summarisation for whole fruit or freeze-dried or powdered fruit interventions

\begin{tabular}{|c|c|c|c|c|c|c|c|c|c|c|c|c|c|}
\hline Supplementation & Study & FMD & SBP & DBP & PWV & Triglycerides & Total cholesterol & LDL-C & HDL-C & ICAM/sICAM & $\mathrm{VCAM} / \mathrm{sVCAM}$ & hsCRP & NO \\
\hline \multirow[t]{5}{*}{$\begin{array}{l}\text { Blueberry or } \\
\text { blueberry powder }\end{array}$} & $\begin{array}{l}\text { Curtis et al. (2019). } \\
\text { UK-blueberry powder }\end{array}$ & $\uparrow$ & - & - & - & - & - & - & $\uparrow$ & & & & - \\
\hline & $\begin{array}{l}\text { Johnson et al. } 2015 \\
\text { (US)-freeze-dried } \\
\text { blueberry powder }\end{array}$ & & $\downarrow$ & $\downarrow$ & $\downarrow$ & & & & & & & - & $\uparrow$ \\
\hline & $\begin{array}{l}\text { McAnulty et al. } 2014 \\
\text { (US)-blueberry powder }\end{array}$ & & - & $\downarrow$ & - & & & & & & & & \\
\hline & $\begin{array}{l}\text { Riso et al. } 2013 \text { (Italy)- } \\
\text { freeze-dried blueberry } \\
\text { powder }\end{array}$ & & - & - & & & - & - & - & - & - & - & \\
\hline & $\begin{array}{l}\text { Stull et al. } 2015 \text { (US)- } \\
\text { freeze-dried blueberry } \\
\text { powder }\end{array}$ & & - & - & & - & - & - & - & & & & \\
\hline \multirow[t]{3}{*}{ Grape powder } & $\begin{array}{l}\text { Barona et al. } 2012 \\
\text { (Colombia)-freeze- } \\
\text { dried red, green and } \\
\text { blue-black grapes } \\
\text { powder }\end{array}$ & $\uparrow$ & $\downarrow$ & - & & - & & & - & $\downarrow$ & - & & - \\
\hline & $\begin{array}{l}\text { Bardagy et al. } 2018 \\
\text { (US)-grape powder }\end{array}$ & & & & & - & - & - & - & - & & - & \\
\hline & $\begin{array}{l}\text { Millar } 2018 \text { (US)- } \\
\text { grape powder }\end{array}$ & & & & & - & - & & - & & & & \\
\hline \multirow[t]{2}{*}{ Raspberry powder } & $\begin{array}{l}\text { Jeong et al. } 2014 \\
\text { (Korea)-powdered } \\
\text { black raspberry }\end{array}$ & $\uparrow$ & & & & - & $\downarrow$ & - & - & - & - & - & \\
\hline & $\begin{array}{l}\text { Jeong et al. } 2016 \\
\text { (Korea)-powdered } \\
\text { black raspberry }\end{array}$ & & - & - & & & & & & - & - & - & \\
\hline $\begin{array}{l}\text { Freeze-dried } \\
\text { strawberry }\end{array}$ & $\begin{array}{l}\text { Basu et al. } 2014(\mathrm{UK})- \\
\text { freeze dried strawberry }\end{array}$ & & - & - & & - & $\downarrow$ & $\downarrow$ & - & - & - & - & \\
\hline $\begin{array}{l}\text { Blackcurrant } \\
\text { powder }\end{array}$ & $\begin{array}{l}\text { Willems et al. } 2015 \\
\text { (UK)-blackcurrant } \\
\text { powder }\end{array}$ & & - & - & & & & & & & & & \\
\hline Citrus fruit & $\begin{array}{l}\text { Dow et al. } 2013 \text { (US)- } \\
\text { low bioactive diet plus } \\
\text { grapefruit }\end{array}$ & & & & & & & & & & - & - & \\
\hline
\end{tabular}

Significant improvement compared to control; Non-significant effects
Significant improvement compared to baseline;

Significant negative effect compared to control; 


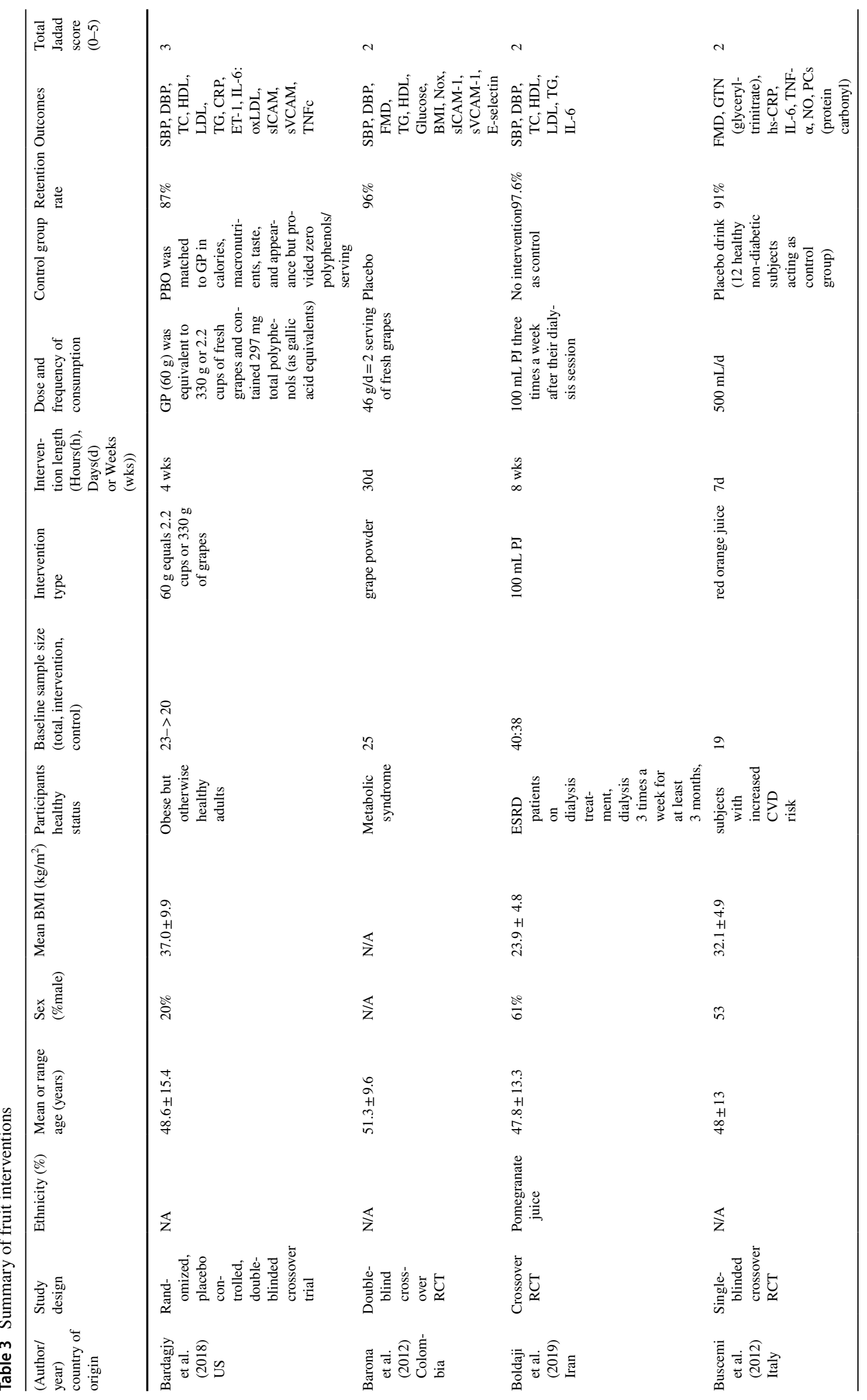




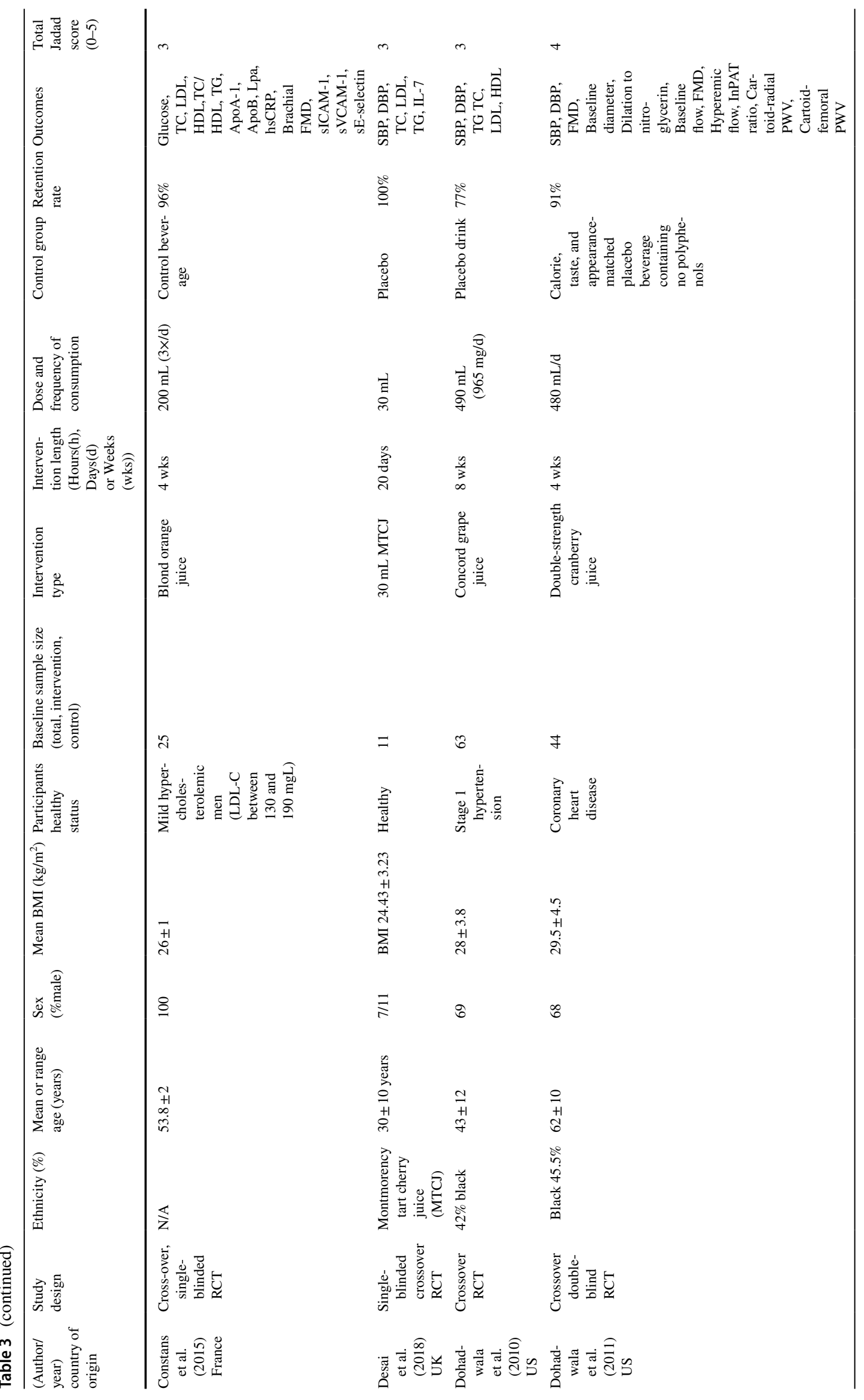




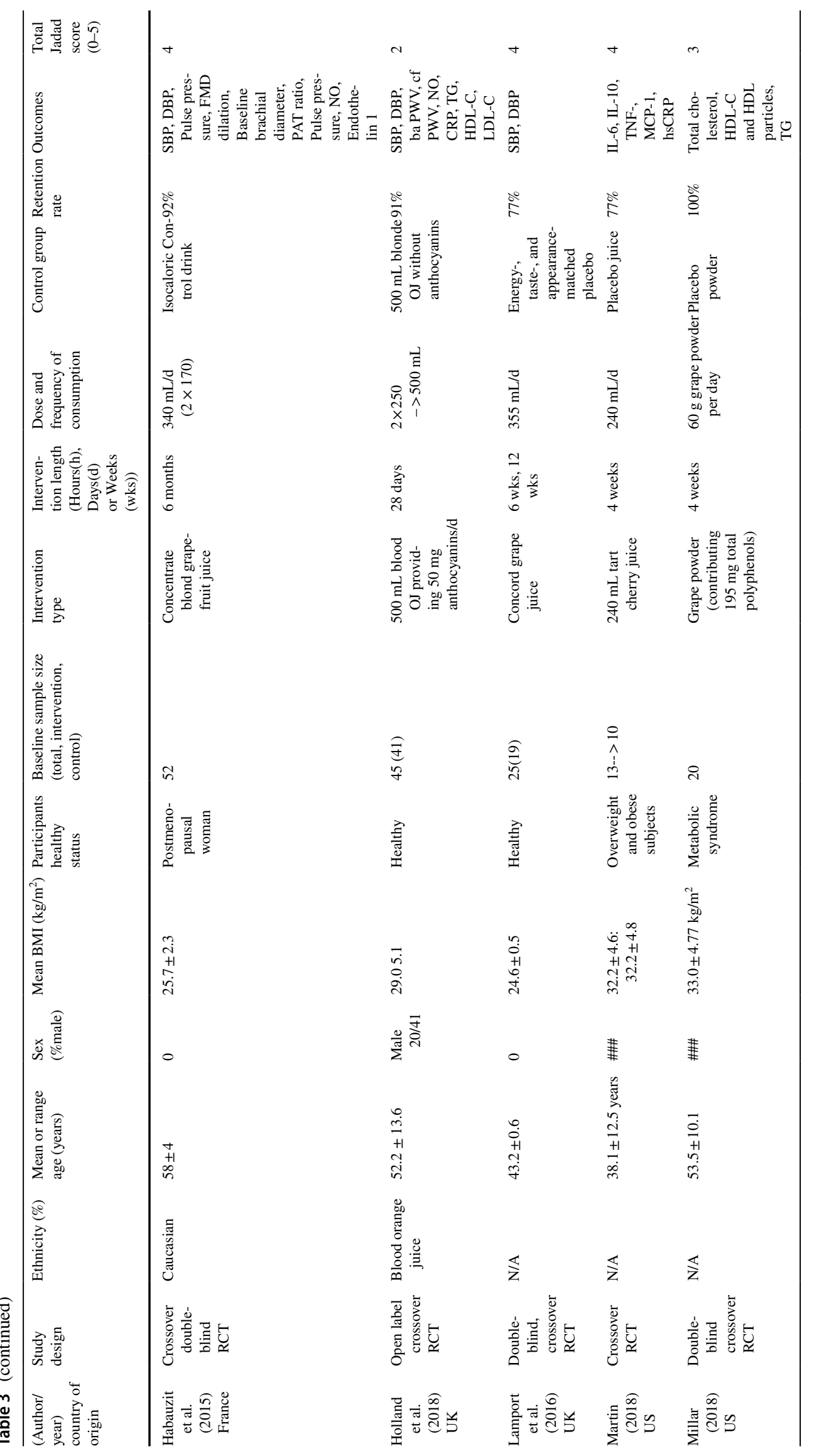




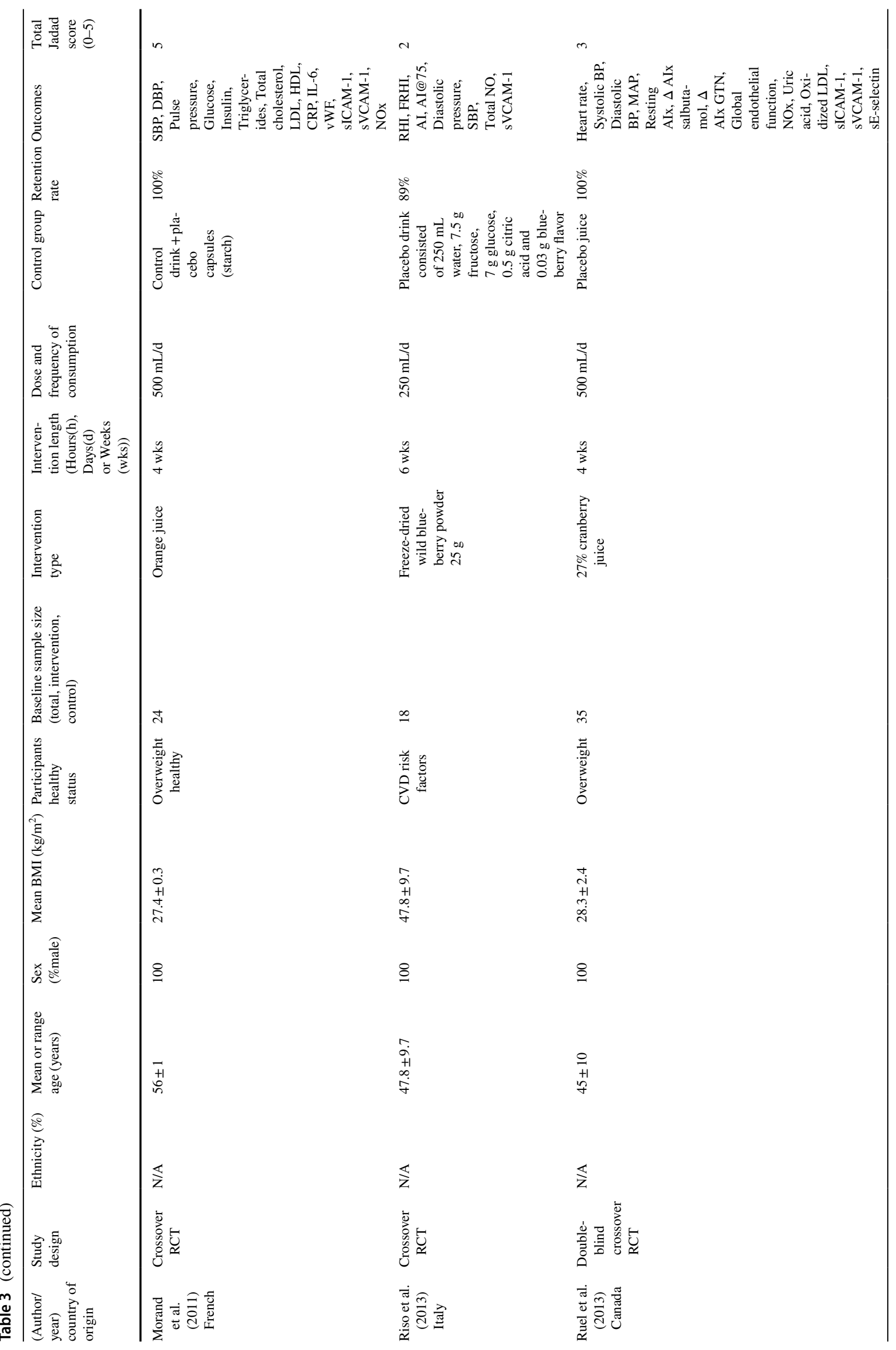




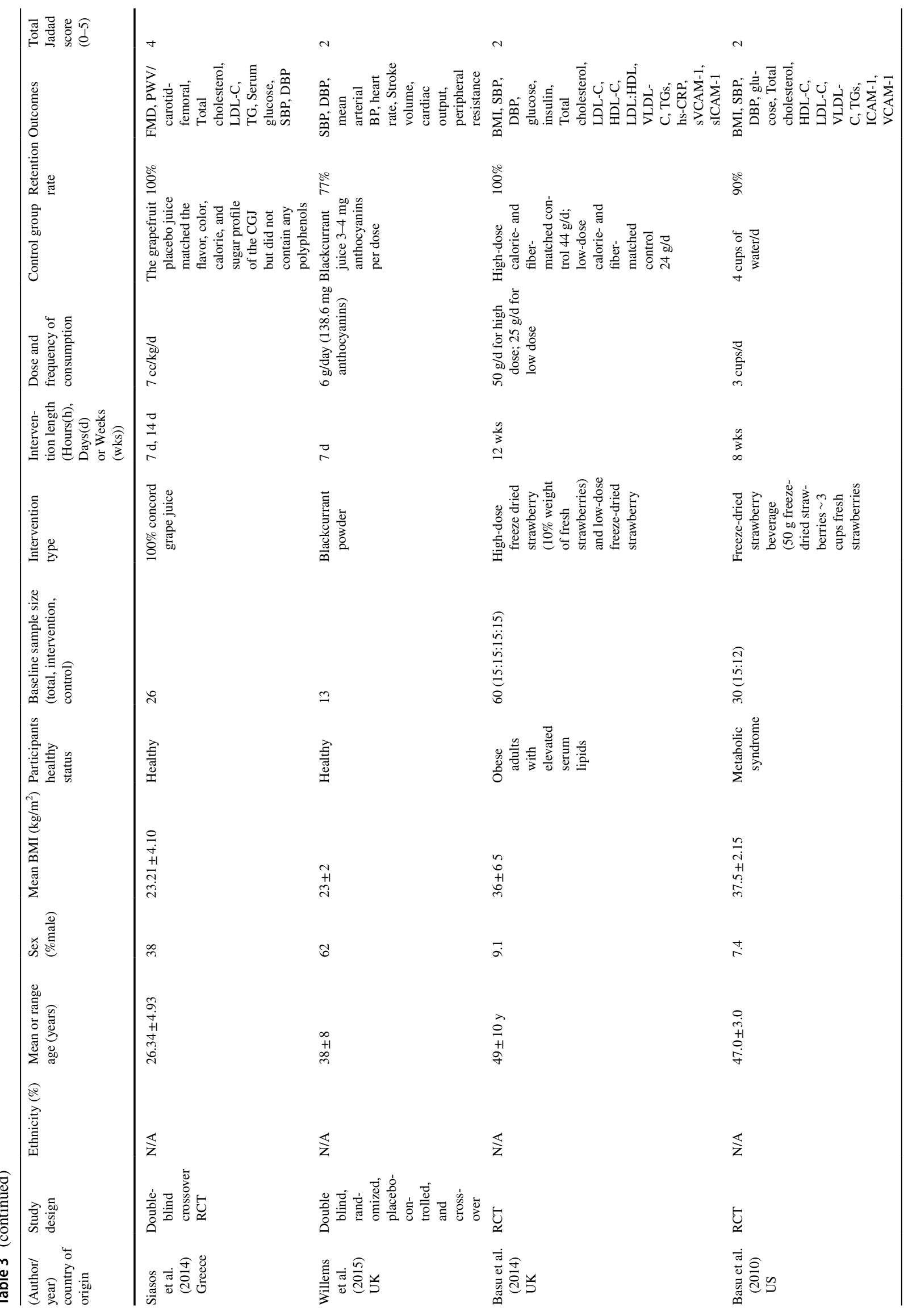




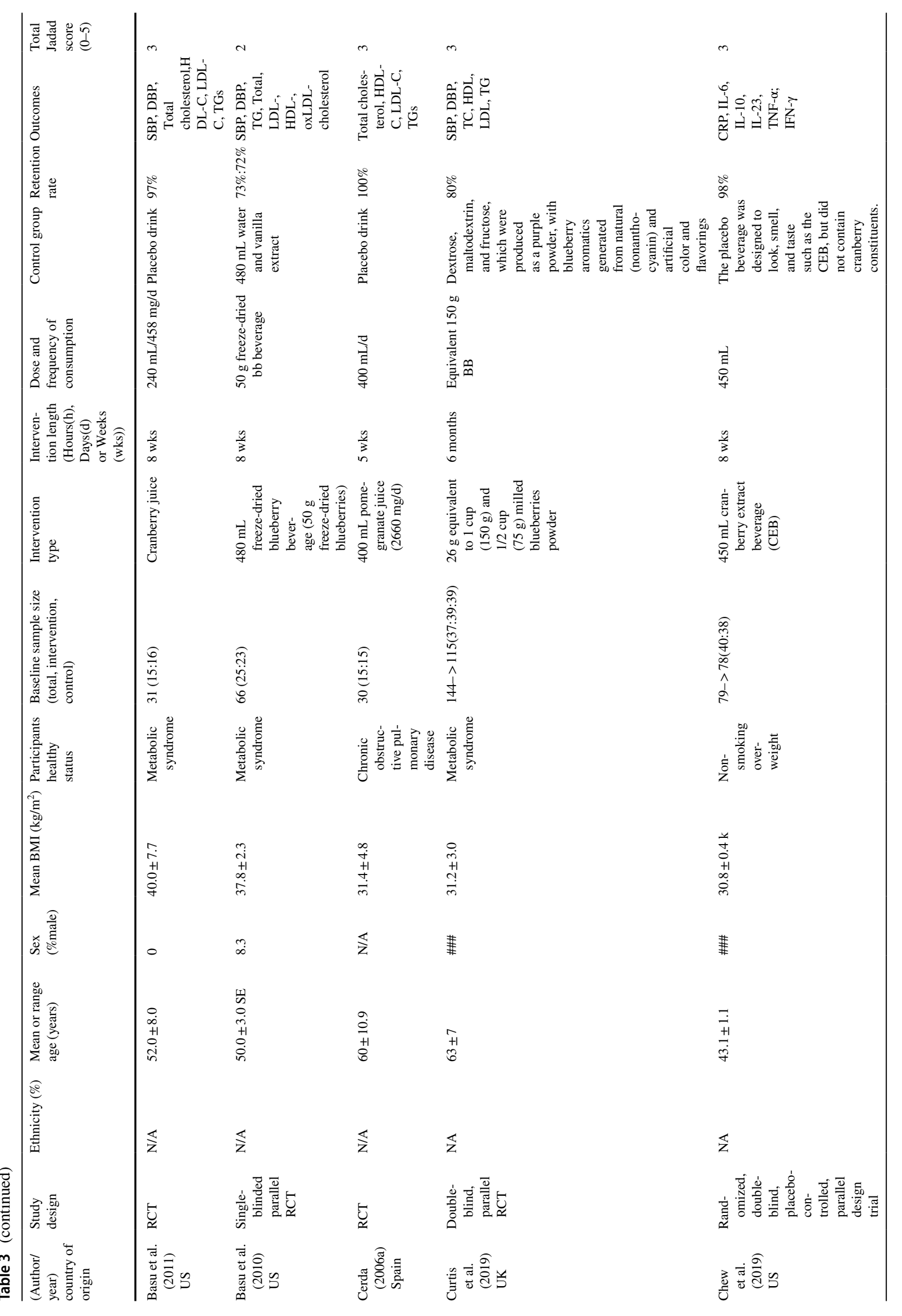




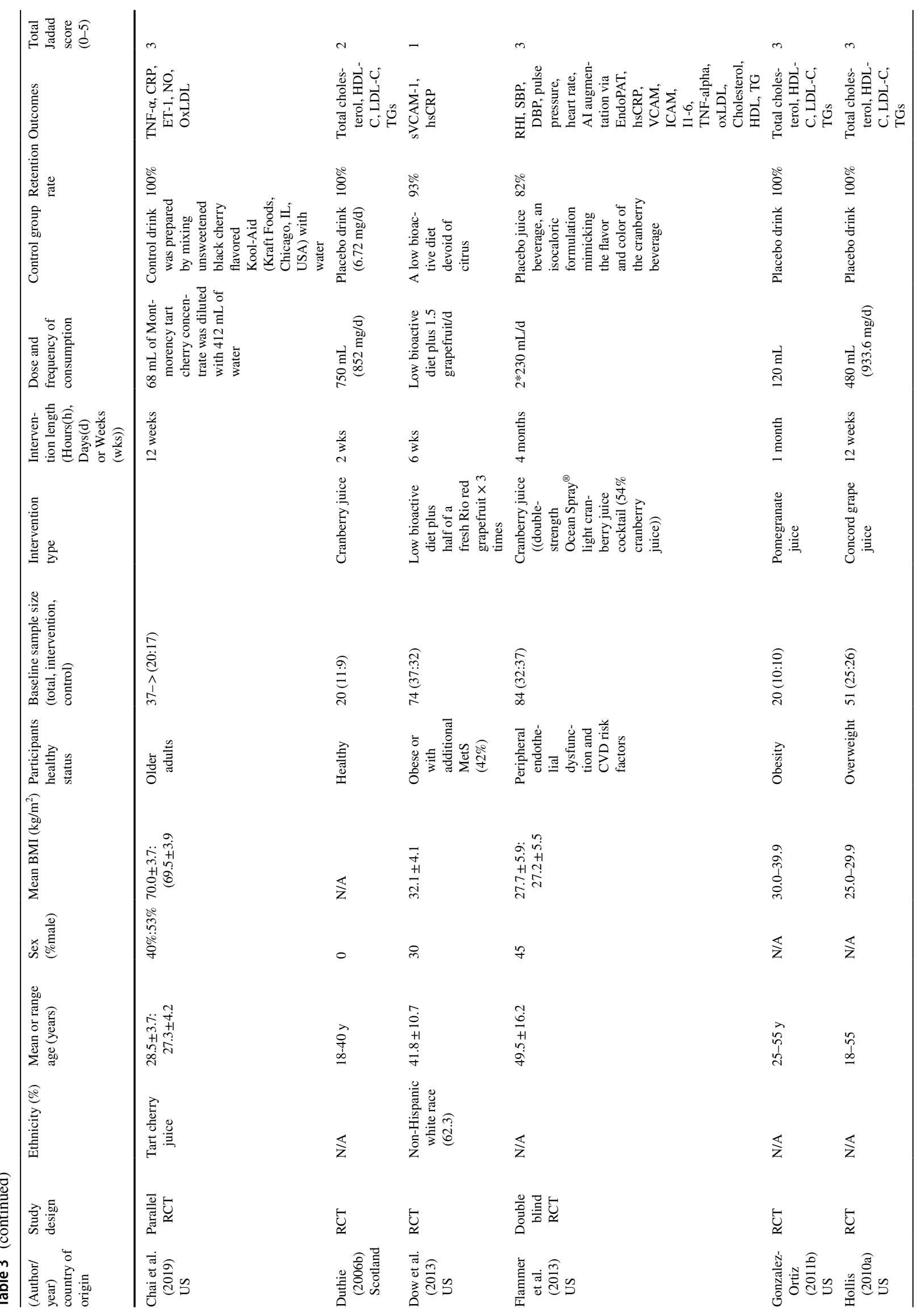




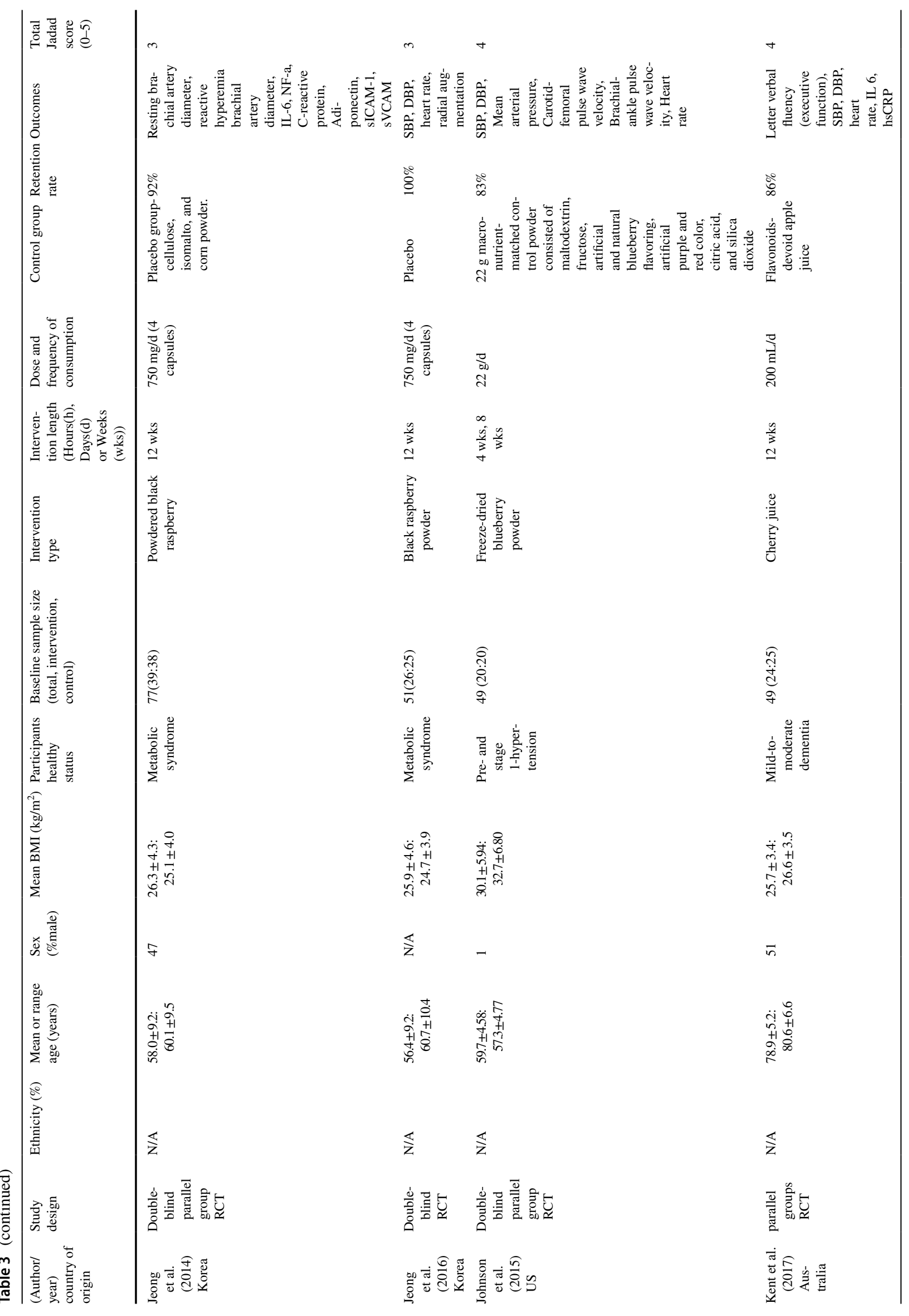




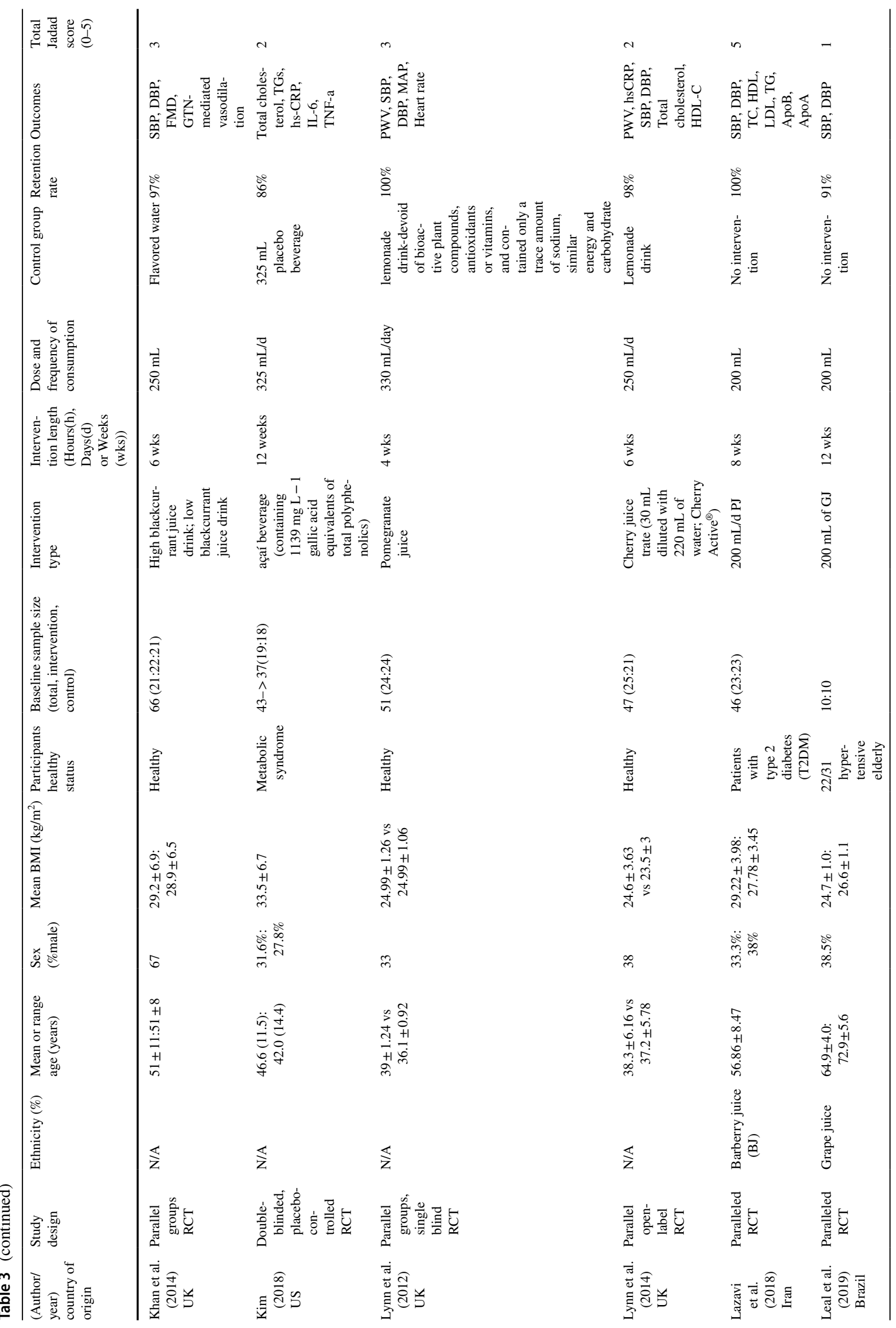




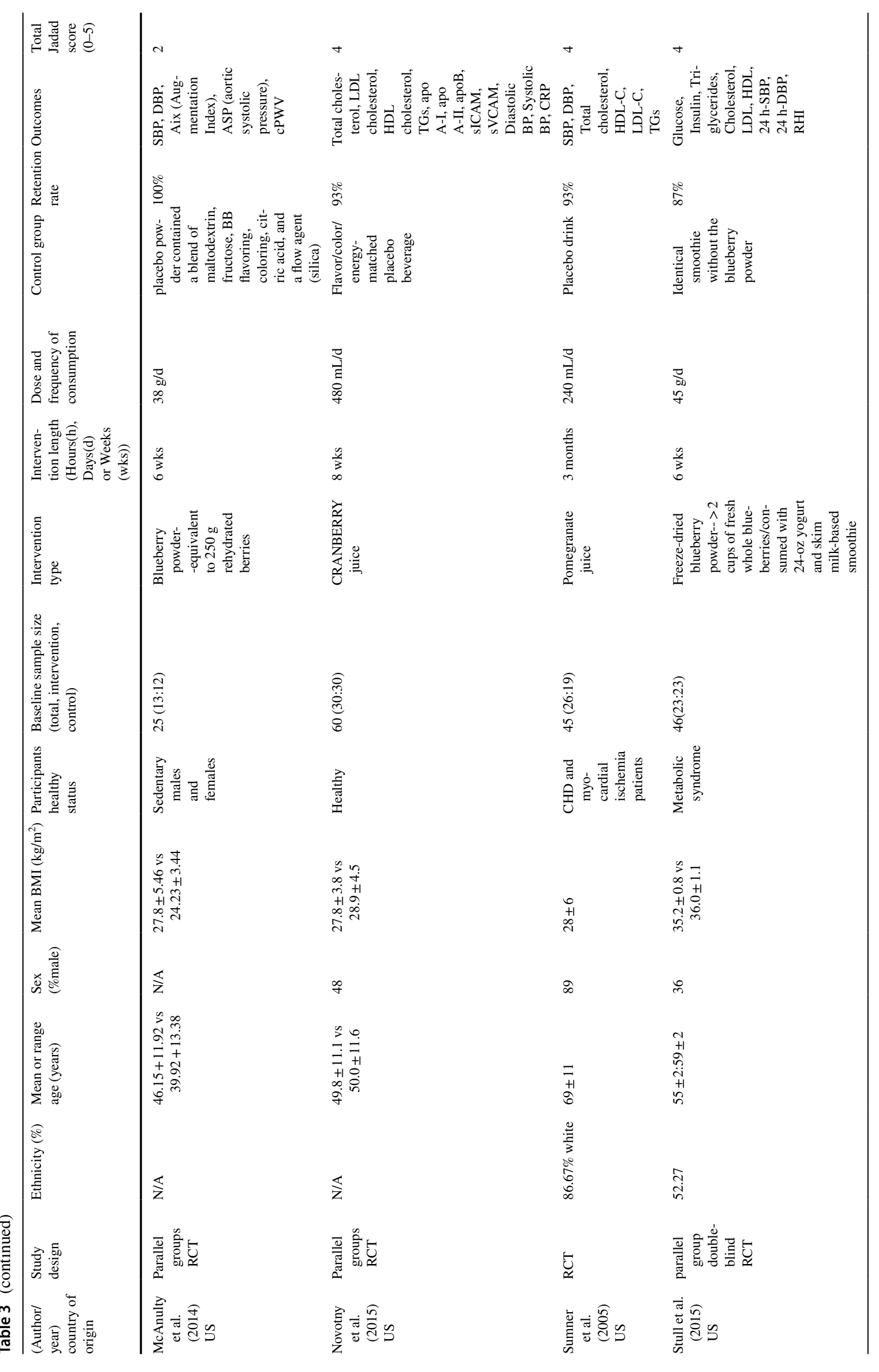


arms of experimental and control groups. The mean chronic treatment duration was 57 days with a standard deviation (SD) of 43 days (ranged from 7 days to 180 days).

Among the fruit juice category, most studies evaluated the effect of cranberry juice, grape juice, pomegranate juice, cherry juice, orange juice ( $n=7,5,5,5,4$, respectively). The mean dosage applied for these types of juices was $480 \mathrm{~mL}$, $353 \mathrm{~mL}, 238 \mathrm{~mL}, 173.6 \mathrm{~mL}$ and $425 \mathrm{~mL}$, respectively. The remaining interventions included blueberry juice $(n=1)$, grapefruit juice $(n=1)$, barberry juice $(n=1)$, blackcurrant juice $(n=1)$, strawberry juice $(n=1)$ and acai berry juice $(n=1)$ (see Table 1). In Table 2, four trials supplemented freeze-dried blueberry powder. Portion conversion of powder to whole fruit was provided in each study; typically the mean dosage of blueberry powder supplementations was $32.75 \mathrm{~g}$ (equivalent to approximately 1.5 cups of fresh blueberries). Three trials supplemented freeze-dried grape powder. The mean dosage of grape powder supplemented was $55.33 \mathrm{~g}$, which is equivalent to approximately 2.5 cups of fresh grapes. The remaining 5 studies supplemented other berries (powdered raspberry, powdered blackcurrant, freezedried strawberry) and citrus fruit (1.5 portion of grapefruit following a low bioactive diet).

\section{Study quality}

The average retention rate for all included trials was $92.64 \%$, of which 30 out of 45 RCTs obtained no less than 3 points of total Jadad score (see Table 3). Trials generally provided adequate description of methods and procedures, although only $40 \%$ of RCTs implemented true randomisation with an adequate description of methods (i.e. computerised statistical randomisation) and $33.33 \%$ of RCTs reported implementing blinding processes, where the placebo were colour and taste matched to mask treatments, and the received treatment was not revealed until the statistical analysis was completed for double blinding. However, there was no report assessing participants' blinding for instance by guessing the treatment they received (Supplemental Table 5).

\section{Meta-analysis of CVD risk factors}

Thirty-eight trials were included in the meta-analysis. The meta-analysis of 38 studies assessing FMD, PWV, SBP, DBP, levels of TAG, TC, HDL-C and LDL-C and levels of vascular inflammatory biomarkers ICAMs, VCAMs, hsCRP and $\mathrm{NO}$ are displayed in forest plots (Figs. 2, 3, 4, 5 and Supplemental Figs. 2-17). The interventions used in these studies supplemented: blueberry powder, grape juice and grape powder, cranberry juice, orange juice, whole grapefruit, pomegranate juice, raspberry powder, freeze-dried strawberry, acai berry juice and barberry juice. Among investigated outcomes, no significant improvements were shown to either FMD or PWV in the treatment group relative to the control group (Fig. 2). The $I^{2}$ test suggested no heterogeneity for interventions assessing the effect on FMD $\left(I^{2}=0 \%, P=0.39\right)$ and non-significant moderate heterogeneities for interventions assessing the effect on PWV $\left(I^{2}=58 \%, P=0.07\right)$.

Our principal findings from a meta-analysis of interventions supplementing with berries (including 531 and 502 treatment participants) including barberry juice, blueberry powder, cranberry juice, freeze-dried strawberry, grape juice, grape powder, pomegranate juice and raspberry powder suggested significantly reduced SBP by $3.68 \mathrm{mmHg}$ [95\% CI -6.79 to $-0.58 ; P=0.02$ ] (Fig. 3) and DBP by $1.78 \mathrm{mmHg}$ [95\% CI -3.43 to $-0.12 ; P=0.04$ ] (Fig. 4), respectively. Subgroup analysis showed that specific interventions using cranberry juice, with mean dosage of $432 \mathrm{~mL}$ and length of 8 weeks, included 149 treatment participants and significantly decreased SBP and DBP by $1.52 \mathrm{mmHg}$ (95\% CI -2.97 to $-0.07 ; P=0.05$ ) (Fig. 3) and $1.52 \mathrm{mmHg}$ (95\% CI -2.87 to $-0.18, P=0.04$ ) (Fig. 4), respectively. Two cherry juice interventions including 36 treatment participants with dosage of $30 \mathrm{~mL}$ for 20 days and $330 \mathrm{~mL}$ for 6 weeks separately also led to a significant reduction in SBP by $3.11 \mathrm{mmHg}(95 \% \mathrm{CI}-4.06$ to $-2.15 ; P=0.02)$ (Fig. 5). Berry group including blueberry juice, cranberry juice, grape powder, pomegranate juice and raspberry powder was also shown to significantly increase sVCAM-1 level by $14.57 \mathrm{ng} / \mathrm{mL}$ ( $95 \%$ CI 4.22 to $24.93, P=0.02$ ) in the treatment group relative to the control (Supplemental Fig. 12). The sensitivity analysis suggested no effect of grapefruit concentrate juice on the result of SBP and no effect of cherry concentrate juice on the results of SBP, DBP (Supplemental Table 6). The $I^{2}$ test suggested significant substantial heterogeneities for berry group investigating the effects on SBP $\left(I^{2}=78 \%, P<0.01\right)$ (Fig. 3$)$ and DBP $\left(I^{2}=78 \%, P<0.01\right)$ (Fig. 4). Funnel plots and the Egger's test for the berry group showed an overall symmetric distribution of the interventions around the standard error for the investigated outcomes of SBP; asymmetric distributions were shown for the berry group investigating the effect on DBP, trim and fill method was further implemented to adjust for the publication bias (Supplemental Fig. 1).

There were no significant effects of other included intervention groups on other vascular and inflammatory markers: TAG (Supplemental Figs. 2, 3), TC (Supplemental Figs. 4, 5), LDL-C (Supplemental Figs. 6, 7), HDL-C (Supplemental Figs. 8, 9), ICAMs (Supplemental Figs. 10, 11), VCAMs (Supplemental Figs. 12, 13), NO (Supplemental Figs. 14, 15), or hsCRP (Supplemental Figs. 16, 17). The $I^{2}$ test suggested significant substantial and moderate heterogeneities for berry group $\left(I^{2}=71 \%, P<0.01\right)$ and cherry juice $\left(I^{2}=55 \%, P=0.14\right)$ investigating the effects on TC, respectively (Supplemental Figs. 4, 5). There are 
significant moderate heterogeneity for berry group investigating the effects on HDL-C $\left(I^{2}=56 \%, P<0.01\right)$ (Supplemental Fig. 8); non-significant moderate heterogeneities were shown for berry group investigating the effects on TAG $\left(I^{2}=36 \%, P=0.08\right)$ (Supplemental Fig. 2), LDL $\left(I^{2}=37 \%\right.$, $P=0.08$ ) (Supplemental Fig. 6). Funnel plots and the Egger's test for the berry group showed an overall symmetric distribution of the interventions around the standard error for the investigated outcomes of TAG, TC, LDL-C (Egger's tests $P>0.05$ ) (Supplemental Fig. 1). Asymmetric distributions were shown for the berry group investigating the effect on TAG, trim and fill method was further implemented to adjust for the publication bias (Supplemental Fig. 1).

\section{Discussion}

\section{Principal findings}

We are continually reminded of the health benefits of consuming more fruit and one consumer-friendly strategy to increase fruit consumption is through juice [12]. Even though the juicing process can influence the nutritional value of fruit; a systematic review has demonstrated that the intake of fruit and vegetable juice offered similar health benefits to the intake of whole fruit and vegetables [16]. The results from our review support the beneficial effects of juice and have revealed the potential of berries, in juiced form, to play a beneficial role in the diet to maintain cardiovascular health. High dose of $432 \mathrm{~mL}$ cranberry juice and small studies of cherry juice using up to $330 \mathrm{~mL}$ showed improvements to blood pressure in our meta-analysis, whereas the National Health Service adult portion size recommendation for fruit juice is no more than $150 \mathrm{~mL}$ per day [75], thus a downsized portion according to daily recommendation should be studied in intervention studies.

These findings suggest that interventions with berries, especially using juiced cranberries or cherries, as the most active substitutes for whole fruit, may effectively reduce SBP and DBP. However, the current analyses do not support the notion that the consumption of fruit powders or other fruit juices will confer a cardiovascular function-protective benefit.

\section{Scientific analysis of findings}

Our review showed that blueberry and grape in both juiced and freeze-dried forms have been frequently studied for their cardio and vascular protective effects, however, this quantitative analysis only supported an improvement on the outcomes by the consumption of cranberry juice and cherry juice.
A previous systematic review investigated the impact of fruit polyphenols on blood lipids $(n=17)$, platelet function $(n=9), \mathrm{BP}(n=9)$ and endothelium-dependent vasodilation (vascular function) $(n=7)$ and suggested that polyphenols from fruits such as pomegranate, purple grapes and berries are particularly effective at preventing hypertension compared to other CVD risk factors [7]. Berries in particular were shown to possess cardio-protective properties; the underlying mechanisms highlighted include inhibitory effects on inflammatory gene expression, oxidative stress, carbohydrate digestive enzymes and foam cell formation as well as increased effect on nitric oxide synthase following anthocyanins, the major polyphenol in berries [8].

A previous meta-analysis has grouped RCTs without separating the type of fruit, thus the magnitude of the effects of different fruit juice interventions were not compared. Their results supported the overall consumption of various fruit juices to significantly lower DBP by $2.07 \mathrm{~mm} \mathrm{Hg}(95 \% \mathrm{CI}$ -3.75 to $-0.39 ; P=0.02$ ), whereas no improvement in SBP or lipid levels was obtained within 8 included RCTs [76]. In comparison with this previous report, the present report confirms the significant effects on DBP and reveals also significant effects on SBP.

In another meta-analysis of 95 prospective studies of fruit and vegetable intake, Aune et al. [2] found that fruit juice intake had little association with CVD and total cancer, while slight inverse associations were observed for CHD with RR (95\% CI) 0.79 (0.63-0.98), stroke with RR (95\% CI) $0.67(0.60-0.76)$ and all-cause mortality with RR (95\% CI) $0.87(0.83-0.91)$ every $100 \mathrm{~g} /$ day increment, however, the very low number of studies $(n=2)$ makes these findings preliminary and more studies are needed before any firm conclusions can be drawn [2]. Furthermore, there is evidence showing that increasing the consumption of fruit juice by one serving per day was associated with a $7 \%$ greater incidence of type 2 diabetes (95\% CI $0.8 \%$ to $14 \%$ ) [77] and there is also greater risk of weight gain with higher consumption of fruit juice, probably because of the high sugar content and excess calories provided [78]. Fruit juice contains quantities of sugar classified as 'free' sugars like sucrose, compared with whole fruit in which the sugars are classified as intrinsic. Increased dietary fructose following sucrose intake is reported to increase de novo lipogenesis (DNL) levels and VLDL, which has been shown to increase the risk of developing non-alcoholic fatty liver disease (NAFLD) [79]. Therefore, cautious interpretations should be made when promoting fruit juice consumption as healthy options to increase fruit and vegetable intake.

Other epidemiological evidence has indicated an inverted association between fruit intake and CVD risk factors. Among 34,492 CVD-free postmenopausal women in the Iowa Women's Health Study with 16 years 


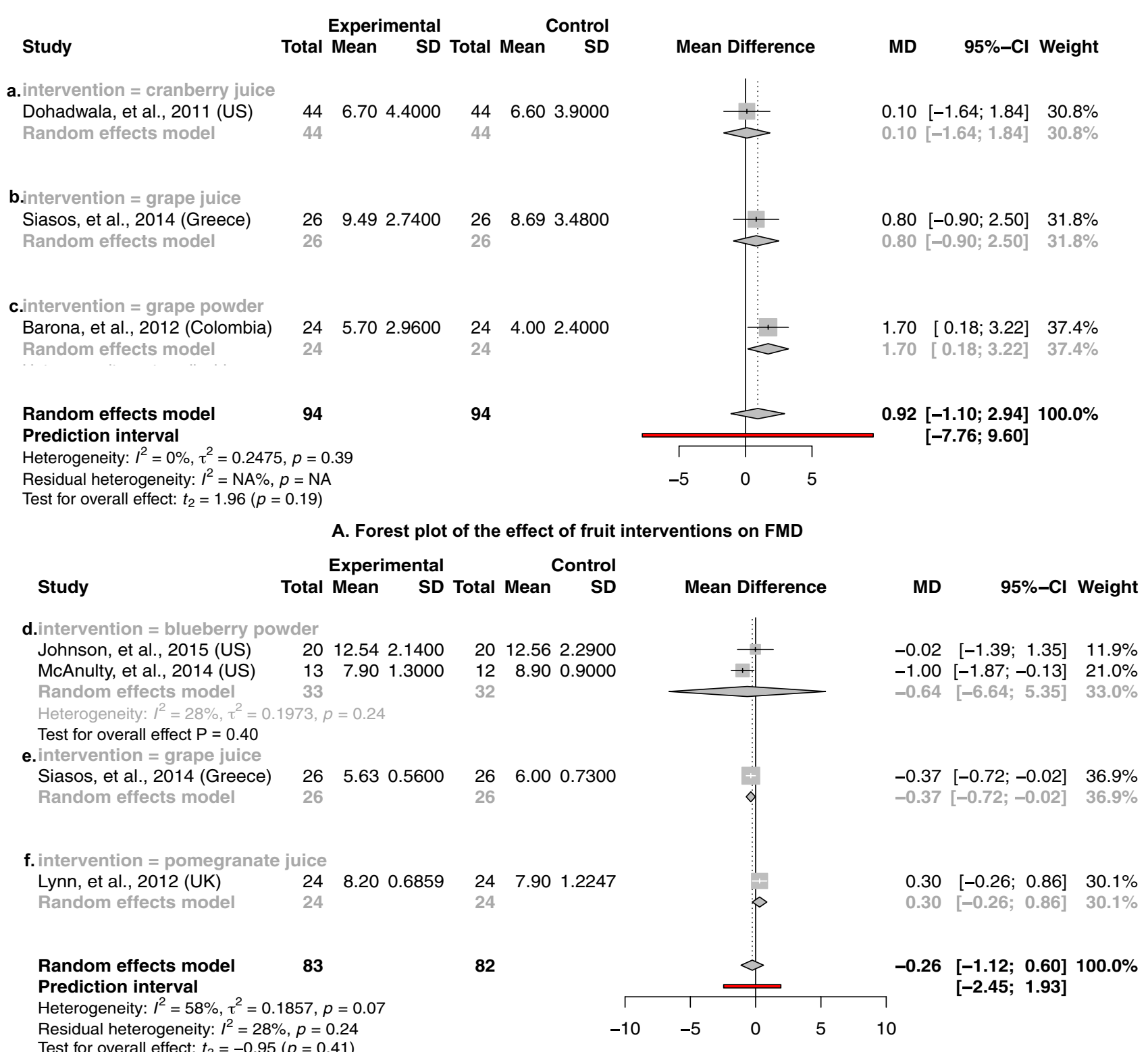

B. Forest plot of the effect of fruit interventions on PWV

\section{*Notes}
a. $480 \mathrm{ml}, 28$ days
b. $240 \mathrm{ml}, 14$ days
c. $46 \mathrm{~g}$, equivalent to 2 cups of grape, 30 days
d. $22 \mathrm{~g}$ or $38 \mathrm{~g}$, equivalent to 1 or 1.5 cups of blueberry, 56 days or 42 days
e. $240 \mathrm{ml}, 14$ days
f. $330 \mathrm{ml}, 28$ days

Fig. 2 The effect of berry interventions including a cranberry juice, $\mathbf{b}$ grape juice and $\mathbf{c}$ grape powder assessing FMD and $\mathbf{d}$ blueberry powder, $\mathbf{e}$ grape juice and $\mathbf{f}$ pomegranate juice assessing PWV

of follow-up, a significantly reduced risk ratio of CVD mortality was associated with intake of at least once per week of apples and pears, oranges, grapefruit, blueberries, strawberries, grapes and raisins after adjustment for age and energy [4]. However, following adjustment for other confounding covariates, the significance was only retained for the intake of strawberries, apples and pears. In a further investigation of strawberry intake for its cross-sectional association with lipids and CRP profiles, only a borderline significance was reported for a reduced 


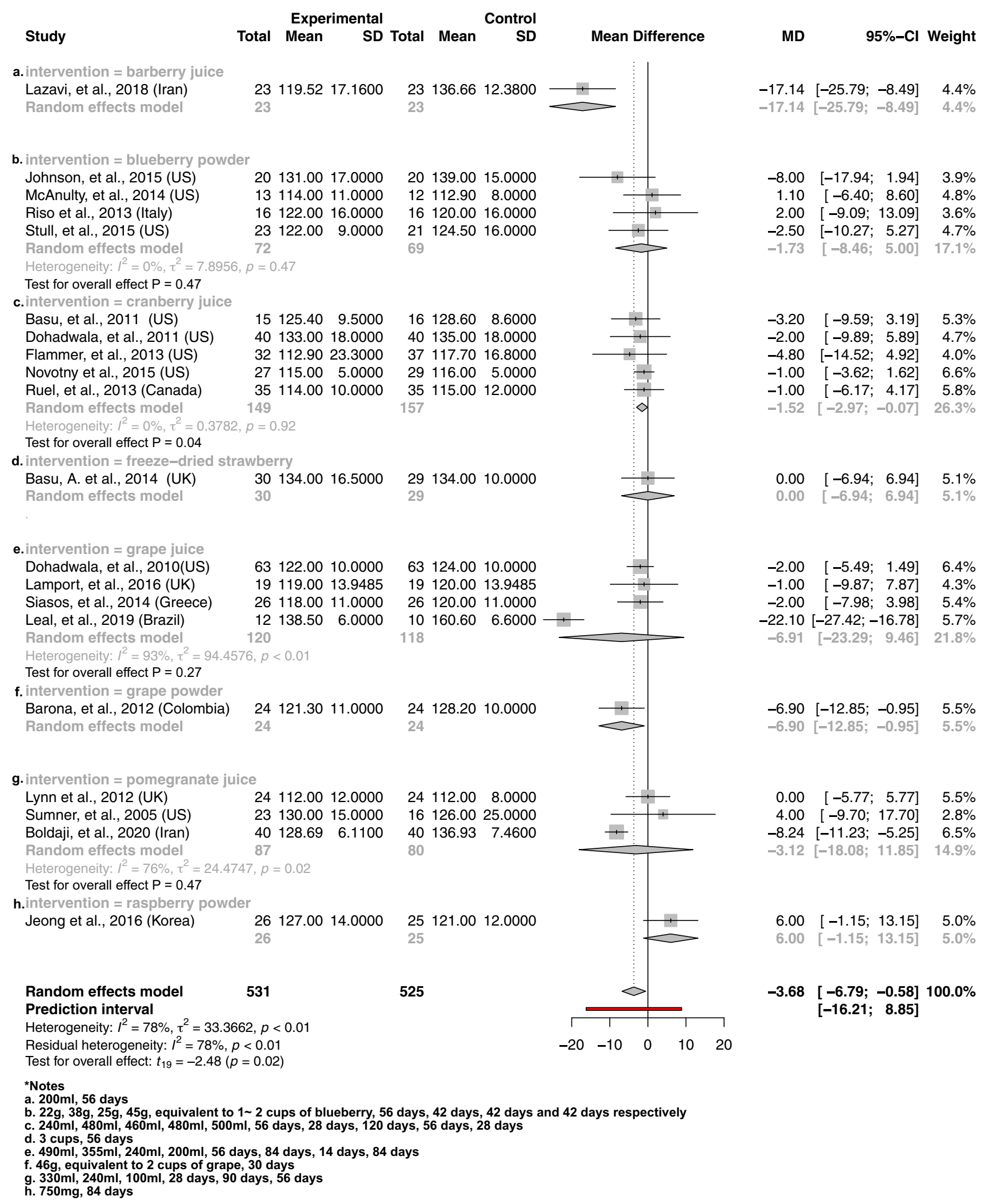

Fig. 3 The effect of berry interventions including a barberry juice, $\mathbf{b}$ blueberry powder, $\mathbf{c}$ cranberry juice, $\mathbf{d}$ freeze-dried strawberry, $\mathbf{e}$ grape juice, $\mathbf{f}$ grape powder, $\mathbf{g}$ pomegranate juice and $\mathbf{h}$ raspberry powder assessing SBP 


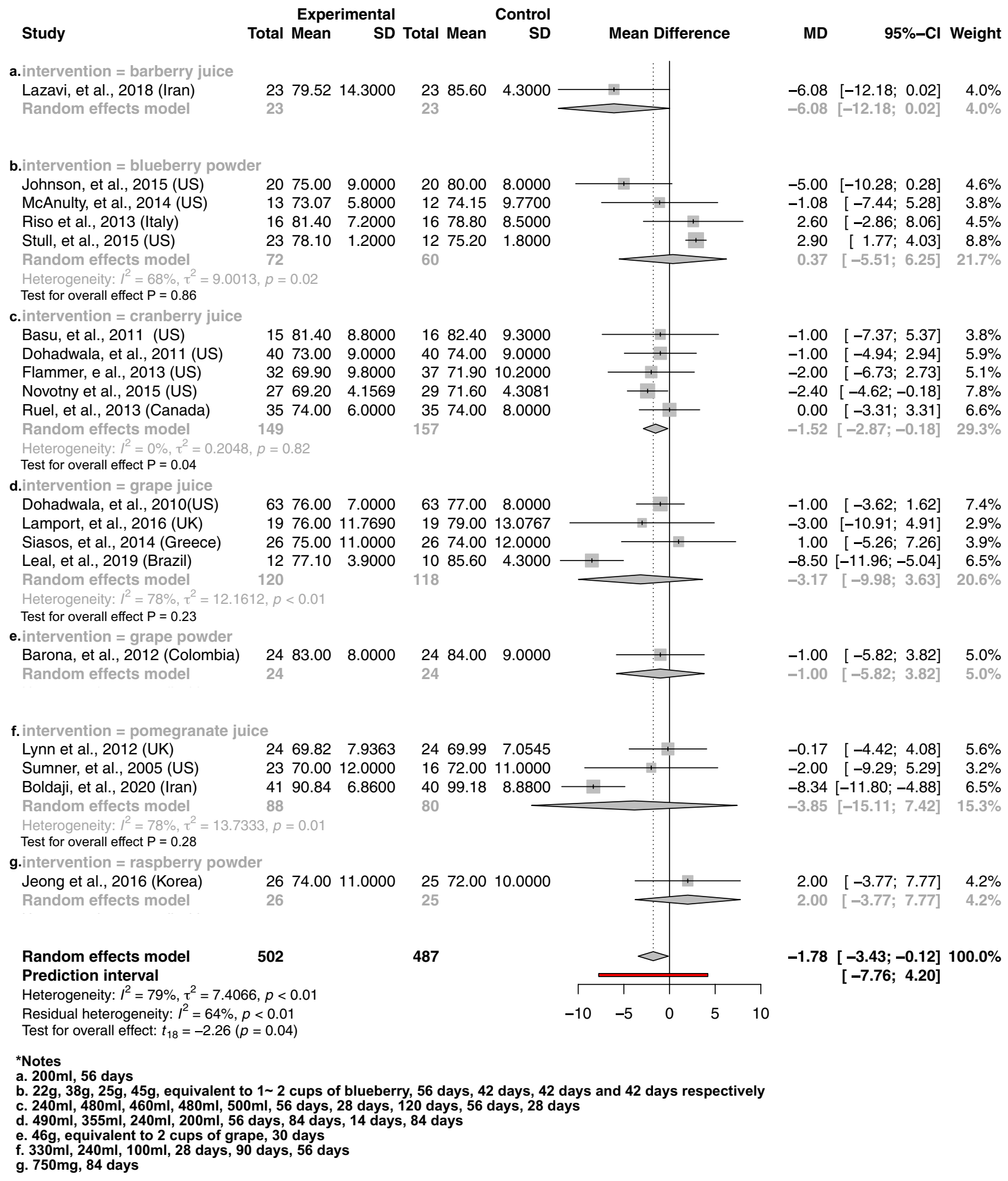

Fig. 4 The effect of berry interventions including a barberry juice, $\mathbf{b}$ blueberry powder, $\mathbf{c}$ cranberry juice, $\mathbf{d}$ grape juice, $\mathbf{e}$ grape powder, $\mathbf{f}$ pomegranate juice and $\mathbf{g}$ raspberry powder assessing DBP

CRP levels [80]. Aune et al. [2] also reported an inverse association between high vs. low berry consumption and all-cause mortality in a meta-analysis, whereas no similar associations were observed for CHD and CVD [2]. 


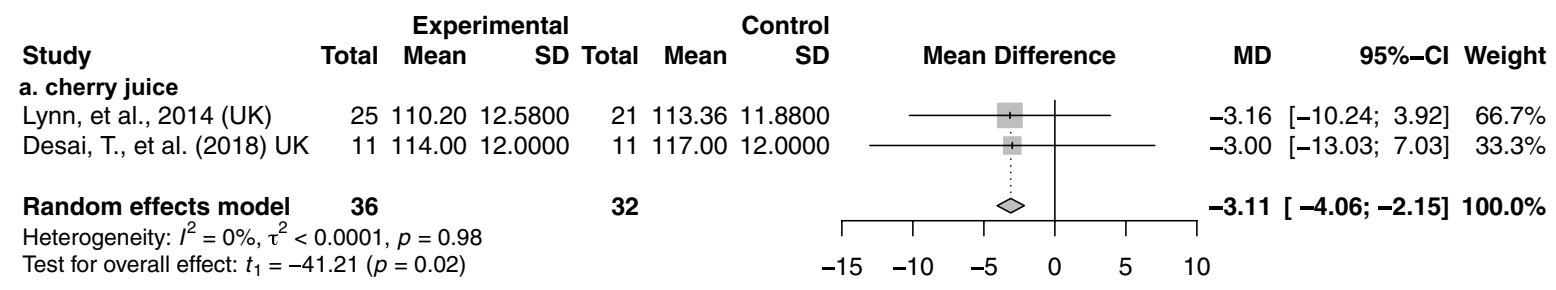

A. Forest plot of the effect of cherry juice interventions on SBP

Study

b.intervention = grapefruit juice

Habauzit, et al., 2015 (France)

Random effects model

c. intervention = orange juice

Morand, et al., 2011 (France)

Hollands, et al., 2018 (UK)

Random effects model

Heterogeneity: $l^{2}=22 \%, \tau^{2}$
Test for overall effect $\mathrm{P}=0.84$

Test for overall effect $\mathrm{P}=0.84$
Random effects model

Prediction interval

Heterogeneity: $I^{2}=0 \%, \tau^{2}=2.8234, p=0.52$

Residual heterogeneity: $I^{2}=22 \%, p=0.26$

Test for overall effect: $t_{2}=0.52(p=0.66)$ 62

\section{Experimental \\ Control}

Total Mean SD Total Mean

SD

SD

\section{Mean Difference}

MD $\quad 95 \%-\mathrm{Cl}$ Weight

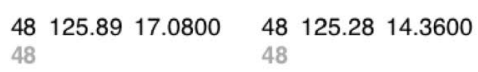

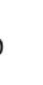

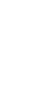

:

$23 \quad 131.30 \quad 12.9487 \quad 23 \quad 134.40 \quad 17.2650$

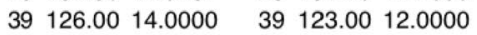
62

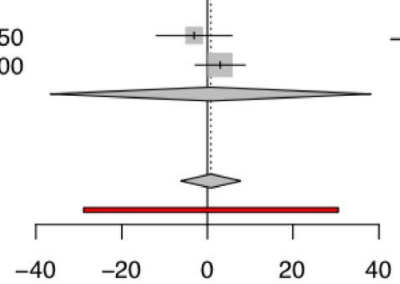

$0.61 \quad[-5.70 ; 6.92] \quad 36.8 \%$ $0.61[-5.70 ; 6.92] \quad 36.8 \%$

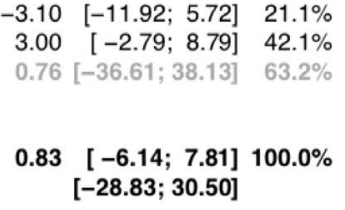

110

B. Forest plot of the effect of citrus juice interventions on SBP

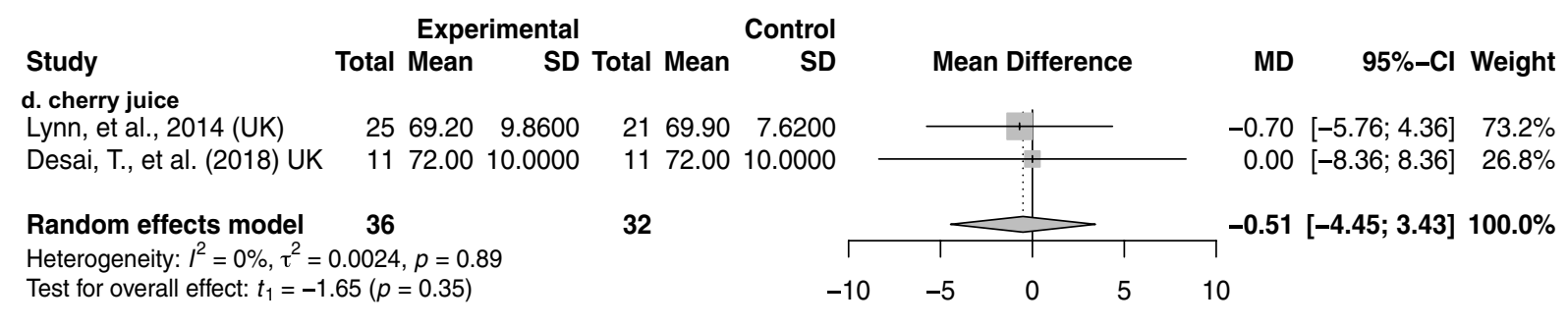

C. Forest plot of the effect of cherry juice interventions on DBP

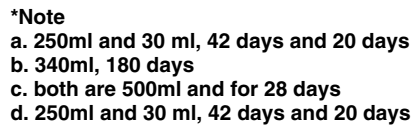

Fig. 5 The effect of $\mathbf{a}$ cherry juice and $\mathbf{b}$ grapefruit juice, $\mathbf{c}$ orange juice interventions assessing SBP and $\mathbf{d}$ cherry juice interventions assessing DBP

Our review has also shown elevated SVCAM-1 level after the berries intervention, however, some authors have suggested that the magnitude of the increase in SVCAM-1 may not be clinically relevant, as the other vascular inflammatory markers did not change between the treatment and the control group after the interventions [41], which is also in line with the results of other inflammatory markers in our review. Aside from this, Bardagjy et al. [41] and Ruel et al. [44] reported significantly higher sVCAM-1 levels in the treatment group at the baseline compared to the control, which may have contributed to the elevated SVCAM level after the interventions in the berries-treated group.
Although the consumption of a range of berries have been linked with improved cardiovascular health, considering the results from our review and previous evidence, current evidence is insufficient and inconsistent to substantiate the consumption of specific berries or other fruit as a cardiovascular-protective dietary strategy.

\section{Implications for health and future research}

Among our results, SBP improved significantly by over $3 \mathrm{mmHg}$ after interventions with specific berries and cherry juice, which may likely have practical implications as blood 
pressure is an important indicator not just for endothelial function, but also for CVD mortality risk [81]. A report from the Joint National Committee and several meta-analyses have estimated that lowering SBP by $5 \mathrm{mmHg}$ or more could decrease stroke risk by $13 \%$ [82], CVD risk by $3 \%$ to $38 \%$ [83], deaths from stroke by $14 \%$, deaths from heart diseases by $9 \%$ and overall mortality by $7 \%$ [84].

However, we only analysed two cherry juice studies with relatively small sample sizes in this review and no other risk factors were improved by this intervention. It would be helpful to have more studies on this topic in order to inform policymakers in nutrition. Future studies on supplementing berries (i.e. cranberries, blueberries, grapes) with a sufficient sample size are warranted, as these appear to have the biggest potential to improve endothelial function and cardiovascular function. Further studies on this topic incorporating effect sizes with interpretation from CVD risk reduction are also required.

\section{Strengths and limitations}

To our knowledge, this is the first systematic review and meta-analysis to compare the impact of fruit in various delivery forms, on cardiovascular health. We also used the newly developed Hartung-Knapp-Sidik-Jonkman method for random-effects model in meta-analysis in addition to a comprehensive search of the literature in the topic. There are limitations to our review, however. As explored by the subgroup analysis, the significant moderate-to-substantial heterogeneity among the berry group majorly contributed to grape juice and pomegranate juice studies (Figs. 3, 4), however, the number of studies within grape juice and pomegranate juice interventions ( $\mathrm{n}$ ranged from 3 to 4 ) were too few to perform subgroup analysis. The high heterogeneity could be explained by the different populations and regions and participant characteristics at baseline within these few studies. Physical activity level has been considered as cofactor, but no adjustments for physical activity level have been applied among the included studies in this review.

There is limited study data under some types of interventions investigating all risk factors (i.e. grape powder and cherry juice) to be meta-analysed; and even though studies supplementing cranberry juice have shown an significant effect, they are not accompanied by improvements to other risk factors and are limited to relatively small sample sizes within 2 studies, so the implications of our results should be treated with caution. Heterogeneities presented in our results, however, were explored by subgroup analyses of different intervention subgroups, due to the limited number of studies under each participants characteristic and country region, we were unable to further compare among different baseline-characterised subjects (i.e. physical activity, gender), regions (i.e. western and other countries) and juice qualities.

\section{Conclusion}

This review has highlighted a scarcity of intervention studies aimed at improving endothelial function and cardiovascular health by consuming berries, citrus and cherries in different forms such as freeze-dried and powdered fruit or as fruit juice. The quantitative analysis led us to further explore the potential of various berries, cherries and citrus-based interventions to improve endothelial function and cardiovascular health. There is a potential for berries in juiced forms to benefit cardio-health, however, these are only suggestive and raised from non-substantial evidence from a few studies within each intervention type. Inconsistent evidence was reported considering results from our analysis along with other reviews regarding the effect of fruit juice on CVD risk factors. More research supplementing summarised interventions in this review is warranted to reinforce the evidence and to further substantiate the health benefits of specific fruit-based interventions.

Author contributions All authors developed the study concept and design and contributed to the critical revision of the manuscript for important intellectual content; YW wrote the draft of manuscript, conducted data extraction and statistical analysis; all authors contributed to discussion and reviewed/edited the manuscript. All authors have read and approved the final version submitted for publication.

Funding This review received no specific grant from any funding agency, commercial or not-for-profit sectors.

\section{Compliance with ethical standards}

Conflict of interest There is no conflict of interest in this review.

Open Access This article is licensed under a Creative Commons Attribution 4.0 International License, which permits use, sharing, adaptation, distribution and reproduction in any medium or format, as long as you give appropriate credit to the original author(s) and the source, provide a link to the Creative Commons licence, and indicate if changes were made. The images or other third party material in this article are included in the article's Creative Commons licence, unless indicated otherwise in a credit line to the material. If material is not included in the article's Creative Commons licence and your intended use is not permitted by statutory regulation or exceeds the permitted use, you will need to obtain permission directly from the copyright holder. To view a copy of this licence, visit http://creativecommons.org/licenses/by/4.0/.

\section{References}

1. WHO (2003) Diet, nutrition and the prevention of chronic diseases. Report of a Joint FAO, WHO Expert Consultation. WHO Technical Report Series. World Helath Organization, Geneva 
2. Aune D, Giovannucci E, Boffetta P, Fadnes LT, Keum N, Norat T, Greenwood DC, Riboli E, Vatten LJ, Tonstad S (2017) Fruit and vegetable intake and the risk of cardiovascular disease, total cancer and all-cause mortality - a systematic review and doseresponse meta-analysis of prospective studies. Int $\mathrm{J}$ Epidemiol 46(3):1029-1056. https://doi.org/10.1093/ije/dyw319

3. Fung TT, Rimm EB, Spiegelman D, Rifai N, Tofler GH, Willett WC, Hu FB (2001) Association between dietary patterns and plasma biomarkers of obesity and cardiovascular disease risk. Am J Clin Nutr 73(1):61-67. https://doi.org/10.1093/ajen/73.1.61

4. Mink PJ, Scrafford CG, Barraj LM, Harnack L, Hong CP, Nettleton JA, Jacobs DR Jr (2007) Flavonoid intake and cardiovascular disease mortality: a prospective study in postmenopausal women. Am J Clin Nutr 85(3):895-909. https://doi.org/10.1093/ ajcn/85.3.895

5. Daiber A, Steven S, Weber A, Shuvaev VV, Muzykantov VR, Laher I, Li H, Lamas S, Münzel T (2017) Targeting vascular (endothelial) dysfunction. Br J Pharmacol 174(12):1591-1619

6. Luscher TF, Vanhoutte PM (2020) The endothelium: modulator of cardiovascular function. CRC Press, Boca Raton

7. Chong MF-F, Macdonald R, Lovegrove JA (2010) Fruit polyphenols and CVD risk: a review of human intervention studies. Br J Nutr 104(S3):S28-S39

8. Basu A, Rhone M, Lyons TJ (2010) Berries: emerging impact on cardiovascular health. Nutr Rev 68(3):168-177

9. Kelley DS, Adkins Y, Laugero KD (2018) A review of the health benefits of cherries. Nutrients 10(3):368. https://doi.org/10.3390/ nu 10030368

10. Zheng J, Zhou Y, Li S, Zhang P, Zhou T, Xu DP, Li HB (2017) Effects and mechanisms of fruit and vegetable juices on cardiovascular diseases. Int J Mol Sci. https://doi.org/10.3390/ijms180305 55

11. Oude Griep LM, Stamler J, Chan Q, Van Horn L, Steffen LM, Miura K, Ueshima H, Okuda N, Zhao L, Daviglus ML, Elliott P, IRG (2013) Association of raw fruit and fruit juice consumption with blood pressure: the INTERMAP Study. Am J Clin Nutr 97(5):1083-1091. https://doi.org/10.3945/ajcn.112.046300

12. Ruxton CHS (2008) Smoothies: one portion or two? Nutr Bull 33:129-132

13. Kamiloglu S, Demirci M, Selen S, Toydemir G, Boyacioglu D, Capanoglu E (2014) Home processing of tomatoes (Solanum lycopersicum): effects on in vitro bioaccessibility of total lycopene, phenolics, flavonoids, and antioxidant capacity. J Sci Food Agric 94(11):2225-2233. https://doi.org/10.1002/jsfa.6546

14. Porrini M, Riso P, Testolin G (1998) Absorption of lycopene from single or daily portions of raw and processed tomato. Br J Nutr 80(4):353-361

15. Langer S, Kennel A, Lodge JK (2018) The influence of juicing on the appearance of blueberry metabolites $2 \mathrm{~h}$ after consumption: a metabolite profiling approach. Br J Nutr 119(11):1233-1244. https://doi.org/10.1017/s0007114518000855

16. Ruxton CHS, Gardner EJ, Walker D (2006) Can pure fruit and vegetable juices protect against cancer and cardiovascular disease too? A review of the evidence. Int J Food Sci Nutr 57(3-4):249272. https://doi.org/10.1080/0963748060085134

17. Blanch N, Clifton PM, Keogh JB (2015) A systematic review of vascular and endothelial function: effects of fruit, vegetable and potassium intake. Nutr Metab Cardiovasc Dis 25(3):253-266. https://doi.org/10.1016/j.numecd.2014.10.001

18. Basu A, Penugonda K (2009) Pomegranate juice: a hearthealthy fruit juice. Nutr Rev 67(1):49-56. https://doi.org/10.11 11/j.1753-4887.2008.00133.x

19. Higgins JP, Thomas J, Chandler J, Cumpston M, Li T, Page MJ, Welch VA (2019) Cochrane handbook for systematic reviews of interventions. Wiley, Chichester
20. Tacconelli E (2010) Systematic reviews: CRD's guidance for undertaking reviews in health care. Lancet Infect Dis 10(4):226

21. Moher D, Liberati A, Tetzlaff J, Altman DG (2009) Preferred reporting items for systematic reviews and meta-analyses: the PRISMA statement. Ann Intern Med 151(4):264-269

22. Jadad AR, Moore RA, Carroll D, Jenkinson C, Reynolds DJM, Gavaghan DJ, McQuay HJ (1996) Assessing the quality of reports of randomized clinical trials: is blinding necessary? Control Clin Trials 17(1):1-12

23. Mavridis D, Salanti G (2014) How to assess publication bias: funnel plot, trim-and-fill method and selection models. Royal College of Psychiatrists, London

24. Core Team R (2013) R: a language and environment for statistical computing. R Foundation for Statistical Computing, Vienna

25. Balduzzi S, Rücker G, Schwarzer G (2019) How to perform a meta-analysis with R: a practical tutorial. Evid-Based Mental Health 22(4):153-160

26. Lynn A, Mathew S, Moore CT, Russell J, Robinson E, Soumpasi V, Barker ME (2014) Effect of a Tart Cherry juice supplement on arterial stiffness and inflammation in healthy adults: a randomised controlled trial. Plant Foods Hum Nutr 69(2):122-127. https://doi.org/10.1007/s11130-014-0409-x

27. Habauzit V, Verny MA, Milenkovic D, Barber-Chamoux N, Mazur A, Dubray C, Morand C (2015) Flavanones protect from arterial stiffness in postmenopausal women consuming grapefruit juice for 6 mo: a randomized, controlled, crossover trial. Am J Clin Nutr 102(1):66-74. https://doi.org/10.3945/ ajcn.114.104646

28. Chai SC, Davis K, Zhang Z, Zha L, Kirschner KF (2019) Effects of tart cherry juice on biomarkers of inflammation and oxidative stress in older adults. Nutrients. https://doi.org/10.3390/nu110 20228

29. Krga I, Milenkovic D (2019) Anthocyanins: from sources and bioavailability to cardiovascular-health benefits and molecular mechanisms of action. J Agric Food Chem 67(7):1771-1783. https://doi.org/10.1021/acs.jafc.8b06737

30. Weihrauch JL, Posati LP, Anderson BA, Exler J (1977) Lipid conversion factors for calculating fatty acid contents of foods. J Am Oil Chem Soc. 54(1):36-40

31. IntHout J, Ioannidis JP, Borm GF (2014) The Hartung-KnappSidik-Jonkman method for random effects meta-analysis is straightforward and considerably outperforms the standard DerSimonian-Laird method. BMC Med Res Methodol 14(1):25

32. Higgins JP, Thompson SG, Deeks JJ, Altman DG (2003) Measuring inconsistency in meta-analyses. BMJ 327(7414):557

33. Barona J, Aristizabal JC, Blesso CN, Volek JS, Fernandez ML (2012) Grape polyphenols reduce blood pressure and increase flow-mediated vasodilation in men with metabolic syndrome. J Nutr 142(9):1626-1632. https://doi.org/10.3945/jn.112.162743

34. Buscemi S, Rosafio G, Arcoleo G, Mattina A, Canino B, Montana M, Verga S, Rini G (2012) Effects of red orange juice intake on endothelial function and inflammatory markers in adult subjects with increased cardiovascular risk. Am J Clin Nutr 95(5):10891095. https://doi.org/10.3945/ajcn.111.031088

35. Constans J, Bennetau-Pelissero C, Martin JF, Rock E, Mazur A, Bedel A, Morand C, Bérard AM (2015) Marked antioxidant effect of orange juice intake and its phytomicronutrients in a preliminary randomized cross-over trial on mild hypercholesterolemic men. Clin Nutr 34(6):1093-1100. https://doi.org/10.1016/j. clnu.2014.12.016

36. Dohadwala MM, Holbrook M, Hamburg NM, Shenouda SM, Chung WB, Titas M, Kluge MA, Wang N, Palmisano J, Milbury PE, Blumberg JB, Vita JA (2011) Effects of cranberry juice consumption on vascular function in patients with coronary artery disease. Am J Clin Nutr 93(5):934-940. https://doi.org/10.3945/ ajcn. 110.004242 
37. Morand C, Dubray C, Milenkovic D, Lioger D, Martin JF, Scalbert A, Mazur A (2011) Hesperidin contributes to the vascular protective effects of orange juice: a randomized crossover study in healthy volunteers. Am J Clin Nutr 93(1):73-80. https://doi. org/10.3945/ajen.110.004945

38. Riso P, Klimis-Zacas D, Del Bo C, Martini D, Campolo J, Vendrame S, Møller P, Loft S, De Maria R, Porrini M (2013) Effect of a wild blueberry (Vaccinium angustifolium) drink intervention on markers of oxidative stress, inflammation and endothelial function in humans with cardiovascular risk factors. Eur J Nutr 52(3):949-961. https://doi.org/10.1007/s0039 4-012-0402-9

39. Siasos G, Tousoulis D, Kokkou E, Oikonomou E, Kollia M-E, Verveniotis A, Gouliopoulos N, Zisimos K, Plastiras A, Maniatis K, Stefanadis C (2014) Favorable effects of concord grape juice on endothelial function and arterial stiffness in healthy smokers. Am J Hypertens 27(1):38-45. https://doi.org/10.1093/ajh/hpt176

40. Willems ME, Myers SD, Gault ML, Cook MD (2015) Beneficial physiological effects with blackcurrant intake in endurance athletes. Int J Sport Nutr Exerc Metab 25(4):367-374. https://doi. org/10.1123/ijsnem.2014-0233

41. Bardagjy AS, Hu Q, Giebler KA, Ford A, Steinberg FM (2018) Effects of grape consumption on biomarkers of inflammation, endothelial function, and PBMC gene expression in obese subjects. Arch Biochem Biophys 646:145-152. https://doi. org/10.1016/j.abb.2018.04.003

42. Barati Boldaji R, Akhlaghi M, Sagheb MM, Esmaeilinezhad Z (2020) Pomegranate juice improves cardiometabolic risk factors, biomarkers of oxidative stress and inflammation in hemodialysis patients: a randomized crossover trial. J Sci Food Agric 100(2):846-854. https://doi.org/10.1002/jsfa.10096

43. Hollands WJ, Armah CN, Doleman JF, Perez-Moral N, Winterbone MS, Kroon PA (2018) 4-Week consumption of anthocyaninrich blood orange juice does not affect LDL-cholesterol or other biomarkers of CVD risk and glycaemia compared with standard orange juice: a randomised controlled trial. Br J Nutr 119(4):415421. https://doi.org/10.1017/s0007114517003865

44. Ruel G, Lapointe A, Pomerleau S, Couture P, Lemieux S, Lamarche B, Couillard C (2013) Evidence that cranberry juice may improve augmentation index in overweight men. Nutr Res (New York, NY) 33(1):41-49. https://doi.org/10.1016/j.nutre s.2012.11.002

45. Desai T, Bottoms L, Roberts M (2018) The effects of Montmorency tart cherry juice supplementation and FATMAX exercise on fat oxidation rates and cardio-metabolic markers in healthy humans. Eur J Appl Physiol 118(12):2523-2539. https://doi. org/10.1007/s00421-018-3978-9

46. Dohadwala MM, Hamburg NM, Holbrook M, Kim BH, Duess M-A, Levit A, Titas M, Chung WB, Vincent FB, Caiano TL, Frame AA, Keaney JF Jr, Vita JA (2010) Effects of Concord grape juice on ambulatory blood pressure in prehypertension and stage 1 hypertension. Am J Clin Nutr 92(5):1052-1059. https:// doi.org/10.3945/ajcn.2010.29905

47. Lamport DJ, Lawton CL, Merat N, Jamson H, Myrissa K, Hofinan D, Chadwick HK, Quadt F, Wightman JD, Dye L (2016) Concord grape juice, cognitive function, and driving performance: a 12-wk, placebo-controlled, randomized crossover trial in mothers of preteen children. Am J Clin Nutr 103(3):775-783. https://doi. org/10.3945/ajen.115.114553

48. Martin KR, Burrell L, Bopp J (2018) Authentic tart cherry juice reduces markers of inflammation in overweight and obese subjects: a randomized, crossover pilot study. Food Funct 9(10):5290-5300. https://doi.org/10.1039/c8fo01492b

49. Millar CL, Duclos Q, Garcia C, Norris GH, Lemos BS, DiMarco DM, Fernandez ML, Blesso CN (2018) Effects of freeze-dried grape powder on high-density lipoprotein function in adults with metabolic syndrome: a randomized controlled pilot study. Metab Syndr Relat Disord 16(9):464-469. https://doi.org/10.1089/ met.2018.0052

50. McAnulty LS, Collier SR, Landram MJ, Whittaker DS, Isaacs SE, Klemka JM, Cheek SL, Arms JC, McAnulty SR (2014) Six weeks daily ingestion of whole blueberry powder increases natural killer cell counts and reduces arterial stiffness in sedentary males and females. Nutr Res 34(7):577-584. https://doi.org/10.1016/j.nutre s.2014.07.002

51. Novotny JA, Baer DJ, Khoo C, Gebauer SK, Charron CS (2015) Cranberry juice consumption lowers markers of cardiometabolic risk, including blood pressure and circulating C-reactive protein, triglyceride, and glucose concentrations in adults. J Nutr 145(6):1185-1193. https://doi.org/10.3945/jn.114.203190

52. Stull AJ, Cash KC, Champagne CM, Gupta AK, Boston R, Beyl RA, Johnson WD, Cefalu WT (2015) Blueberries improve endothelial function, but not blood pressure, in adults with metabolic syndrome: a randomized, double-blind, placebo-controlled clinical trial. Nutrients 7(6):4107-4123. https://doi.org/10.3390/ nu7064107

53. Lynn A, Hamadeh H, Leung WC, Russell JM, Barker ME (2012) Effects of pomegranate juice supplementation on pulse wave velocity and blood pressure in healthy young and middle-aged men and women. Plant Foods Hum Nutr 67(3):309-314. https:// doi.org/10.1007/s11130-012-0295-Z

54. Khan F, Ray S, Craigie AM, Kennedy G, Hill A, Barton KL, Broughton J, Belch JJF (2014) Lowering of oxidative stress improves endothelial function in healthy subjects with habitually low intake of fruit and vegetables: a randomized controlled trial of antioxidant- and polyphenol-rich blackcurrant juice. Free Radical Biol Med 72:232-237. https://doi.org/10.1016/j.freer adbiomed.2014.04.006

55. Kent K, Charlton K, Roodenrys S, Batterham M, Potter J, Traynor V, Gilbert H, Morgan O, Richards R (2017) Consumption of anthocyanin-rich cherry juice for 12 weeks improves memory and cognition in older adults with mild-to-moderate dementia. Eur J Nutr 56(1):333-341. https://doi.org/10.1007/s00394-015-1083-y

56. Johnson SA, Figueroa A, Navaei N, Wong A, Kalfon R, Ormsbee LT, Feresin RG, Elam ML, Hooshmand S, Payton ME, Arjmandi BH (2015) Daily blueberry consumption improves blood pressure and arterial stiffness in postmenopausal women with preand stage 1-hypertension: a randomized, double-blind, placebocontrolled clinical trial. J Acad Nutr Diet 115(3):369-377. https ://doi.org/10.1016/j.jand.2014.11.001

57. Jeong HS, Hong SJ, Lee TB, Kwon JW, Jeong JT, Joo HJ, Park JH, Ahn CM, Yu CW, Lim DS (2014) Effects of black raspberry on lipid profiles and vascular endothelial function in patients with metabolic syndrome. Phytother Res 28(10):1492-1498. https:// doi.org/10.1002/ptr.5154

58. Dow CA, Wertheim BC, Patil BS, Thomson CA (2013) Daily consumption of grapefruit for 6 weeks reduces urine f2-isoprostanes in overweight adults with high baseline values but has no effect on plasma high-sensitivity c-reactive protein or soluble vascular cellular adhesion molecule 1. J Nutr 143(10):1586-1592. https:// doi.org/10.3945/jn.113.175166

59. Basu A, Fu DX, Wilkinson M, Simmons B, Wu M, Betts NM, Du M, Lyons TJ (2010) Strawberries decrease atherosclerotic markers in subjects with metabolic syndrome. Nutr Res (New York, NY) 30(7):462-469. https://doi.org/10.1016/j.nutres.2010.06.016

60. Basu A, Du M, Leyva MJ, Sanchez K, Betts NM, Wu M, Aston CE, Lyons TJ (2010) Blueberries decrease cardiovascular risk factors in obese men and women with metabolic syndrome. J Nutr 140(9):1582-1587. https://doi.org/10.3945/jn.110.124701

61. Basu A, Betts NM, Nguyen A, Newman ED, Fu D, Lyons TJ (2014) Freeze-dried strawberries lower serum cholesterol and lipid peroxidation in adults with abdominal adiposity and elevated 
serum lipids. J Nutr 144(6):830-837. https://doi.org/10.3945/ jn.113.188169

62. Basu A, Betts NM, Ortiz J, Simmons B, Wu M, Lyons TJ (2011) Low-energy cranberry juice decreases lipid oxidation and increases plasma antioxidant capacity in women with metabolic syndrome. Nutr Res (New York, NY) 31(3):190-196. https://doi. org/10.1016/j.nutres.2011.02.003

63. Cerdá B, Soto C, Albaladejo MD, Martínez P, Sánchez-Gascón F, Tomás-Barberán F, Espín JC (2005) Pomegranate juice supplementation in chronic obstructive pulmonary disease: a 5-week randomized, double-blind, placebo-controlled trial. Eur J Clin Nutr 60:245. https://doi.org/10.1038/sj.ejcn.1602309

64. Duthie SJ, Jenkinson AM, Crozier A, Mullen W, Pirie L, Kyle J, Yap LS, Christen P, Duthie GG (2006) The effects of cranberry juice consumption on antioxidant status and biomarkers relating to heart disease and cancer in healthy human volunteers. Eur J Nutr 45(2):113-122. https://doi.org/10.1007/s00394-005-0572-9

65. González-Ortiz M, Martínez-Abundis E, Espinel-Bermúdez MC, Pérez-Rubio KG (2011) Effect of pomegranate juice on insulin secretion and sensitivity in patients with obesity. Ann Nutr Metab 58(3):220-223. https://doi.org/10.1159/000330116

66. Hollis JH, Houchins JA, Blumberg JB, Mattes RD (2009) Effects of concord grape juice on appetite, diet, body weight, lipid profile, and antioxidant status of adults. J Am Coll Nutr 28(5):574-582

67. Sumner MD, Elliott-Eller M, Weidner G, Daubenmier JJ, Chew MH, Marlin R, Raisin CJ, Ornish D (2005) Effects of pomegranate juice consumption on myocardial perfusion in patients with coronary heart disease. Am J Cardiol 96(6):810-814. https://doi. org/10.1016/j.amjcard.2005.05.026

68. Curtis PJ, Van Der Velpen V, Berends L, Jennings A, Feelisch M, Umpleby AM, Evans M, Fernandez BO, Meiss MS, Minnion M, Potter J, Minihane AM, Kay CD, Rimm EB, Cassidy A (2019) Blueberries improve biomarkers of cardiometabolic function in participants with metabolic syndrome-results from a 6-month, double-blind, randomized controlled trial. Am J Clin Nutr 109(6):1535-1545. https://doi.org/10.1093/ajen/nqy380

69. Chew B, Mathison B, Kimble L, McKay D, Kaspar K, Khoo C, Chen CO, Blumberg J (2019) Chronic consumption of a low calorie, high polyphenol cranberry beverage attenuates inflammation and improves glucoregulation and HDL cholesterol in healthy overweight humans: a randomized controlled trial. Eur J Nutr 58(3):1223-1235. https://doi.org/10.1007/s00394-018-1643-z

70. Lazavi F, Mirmiran P, Sohrab G, Nikpayam O, Angoorani P, Hedayati M (2018) The barberry juice effects on metabolic factors and oxidative stress in patients with type 2 diabetes: a randomized clinical trial. Complement Ther Clin Pract 31:170-174. https:// doi.org/10.1016/j.ctcp.2018.01.009

71. Leal JB, Leal JB, Leal JBP, Borges YD, de Moura MIL, TeixeiraAraujo AA, da Costa VS, Carvalho FO (2019) Grape juice and aerobic exercise on blood pressure. Nutr Food Sci. https://doi. org/10.1108/nfs-08-2019-0256

72. Jeong HS, Hong SJ, Cho JY, Lee TB, Kwon JW, Joo HJ, Park JH, Yu CW, Lim DS (2016) Effects of Rubus occidentalis extract on blood pressure in patients with prehypertension: randomized, double-blinded, placebo-controlled clinical trial. Nutrition (Burbank, Los Angeles County, Calif) 32(4):461-467. https://doi. org/10.1016/j.nut.2015.10.014

73. Kim H, Simbo SY, Fang C, McAlister L, Roque A, Banerjee N, Talcott ST, Zhao H, Kreider RB, Mertens-Talcott SU (2018) Acai (Euterpe oleracea Mart.) beverage consumption improves biomarkers for inflammation but not glucose- or lipid-metabolism in individuals with metabolic syndrome in a randomized, doubleblinded, placebo-controlled clinical trial. Food Funct 9(6):30973103. https://doi.org/10.1039/c8fo00595h

74. Flammer AJ, Martin EA, Goessl M, Widmer RJ, Lennon RJ, Sexton JA, Loeffler D, Khosla S, Lerman LO, Lerman A (2013) Polyphenol-rich cranberry juice has a neutral effect on endothelial function but decreases the fraction of osteocalcin-expressing endothelial progenitor cells. Eur J Nutr 52(1):289-296. https:// doi.org/10.1007/s00394-012-0334-4

75. Guide, NHS Choices Rough. Fruit and Vegetable Portion Sizes. NHS Choices. http://www.nhs.uk/livewell/5aday/documents/ downloads/5aday_portion_guide.pdf. Accessed 25 Sept 2015 [WebCite Cache ID 6bokXyRXx].

76. Liu K, Xing A, Chen K, Wang B, Zhou R, Chen S, Xu H, Mi M (2013) Effect of fruit juice on cholesterol and blood pressure in adults: a meta-analysis of 19 randomized controlled trials. PLoS ONE 8(4):e61420. https://doi.org/10.1371/journal.pone.0061420

77. Imamura F, O'Connor L, Ye Z, Mursu J, Hayashino Y, Bhupathiraju SN, Forouhi NG (2015) Consumption of sugar sweetened beverages, artificially sweetened beverages, and fruit juice and incidence of type 2 diabetes: systematic review, meta-analysis, and estimation of population attributable fraction. BMJ 351:h3576. https://doi.org/10.1136/bmj.h3576

78. Schulze MB, Manson JE, Ludwig DS, Colditz GA, Stampfer MJ, Willett WC, Hu FB (2004) Sugar-sweetened beverages, weight gain, and incidence of type 2 diabetes in young and middleaged women. JAMA 292(8):927-934. https://doi.org/10.1001/ jama.292.8.927

79. Stanhope KL, Schwarz JM, Keim NL, Griffen SC, Bremer AA, Graham JL, Hatcher B, Cox CL, Dyachenko A, Zhang W (2009) Consuming fructose-sweetened, not glucose-sweetened, beverages increases visceral adiposity and lipids and decreases insulin sensitivity in overweight/obese humans. J Clin Investig 119(5):1322-1334

80. Sesso HD, Gaziano JM, Jenkins DJ, Buring JE (2007) Strawberry intake, lipids, C-reactive protein, and the risk of cardiovascular disease in women. J Am Coll Nutr 26(4):303-310

81. van den Hoogen PCW, Feskens EJM, Nagelkerke NJD, Menotti A, Nissinen A, Kromhout D (2000) The relation between blood pressure and mortality due to coronary heart disease among men in different parts of the world. N Engl J Med 342(1):1-8. https:// doi.org/10.1056/nejm200001063420101

82. Reboldi G, Gentile G, Angeli F, Ambrosio G, Mancia G, Verdecchia P (2011) Effects of intensive blood pressure reduction on myocardial infarction and stroke in diabetes: a meta-analysis in 73,913 patients. J Hypertens 29(7):1253-1269. https://doi. org/10.1097/HJH.0b013e3283469976

83. Karmali KN, Lloyd-Jones DM, van der Leeuw J, Goff DC Jr, Yusuf S, Zanchetti A, Glasziou P, Jackson R, Woodward M, Rodgers A, Neal BC, Berge E, Teo K, Davis BR, Chalmers J, Pepine C, Rahimi K, Sundstrom J (2018) Blood pressure-lowering treatment strategies based on cardiovascular risk versus blood pressure: a meta-analysis of individual participant data. PLoS Med 15(3):e1002538. https://doi.org/10.1371/journal.pmed.1002538

84. National Institutes of Health (1997) The sixth report of the Joint National Committee on prevention, detection, evaluation, and treatment of high blood pressure. Arch Intern Med 157(21):2413-46 